\title{
The influence of fault reactivation on injection-induced dynamic triggering of permeability evolution
}

\author{
Elif Cihan Yildirim ${ }^{\oplus},{ }^{1, *}$ Kyungjae $\operatorname{Im}^{1, \dagger}$ and Derek Elsworth ${ }^{1,2,3}$ \\ ${ }^{1}$ Department of Energy and Mineral Engineering, EMS Energy Institute, and G3 Center, The Pennsylvania State University, University Park, PA 16802, USA. \\ E-mail: ecyildirim@tpao.gov.tr \\ ${ }^{2}$ Department of Geosciences, The Pennsylvania State University, University Park, PA 16802, USA. \\ ${ }^{3}$ The EGS Collab Team
}

Accepted 2020 August 3. Received 2020 August 2; in original form 2019 December 6

\begin{abstract}
S UMMAR Y
Mechanisms controlling fracture permeability enhancement during injection-induced and natural dynamic stressing remain unresolved. We explore pressure-driven permeability $(k)$ evolution by step-increasing fluid pressure $(p)$ on near-critically stressed laboratory fractures in shale and schist as representative of faults in sedimentary reservoirs/seals and basement rocks. Fluid is pulsed through the fracture with successively incremented pressure to first examine sub-reactivation permeability response that then progresses through fracture reactivation. Transient pore pressure pulses result in a permeability increase that persists even after the return of spiked pore pressure to the null background level. We show that fracture sealing is systematically reversible with the perturbing pressure pulses and pressure-driven permeability enhancement is eminently reproducible even absent shear slip and in the very short term (order of minutes). These characteristics of the observed fracture sealing following a pressure perturbation appear similar to those of the response by rate-and-state frictional healing upon stress/velocity perturbations. Dynamic permeability increase scales with the pore pressure magnitude and fracture sealing controls the following per-pulse permeability increase, both in the absence and presence of reactivation. However, initiation of the injection-induced reactivation results in a significant increase in the rate of permeability enhancement $(\mathrm{d} k / \mathrm{d} p)$. These results demonstrate the role of frictional healing and sealing of fractures at interplay with other probable processes in pore pressure-driven permeability stimulation, such as particle mobilization.
\end{abstract}

Key words: Fracture and flow; Friction; Permeability and porosity; Geomechanics; Seismic cycle; Induced seismicity.

\section{INTRODUCTION}

A significant portion of fluid flow in the brittle upper crust occurs through high-permeability pathways, such as faults and fractures. Moreover, evidence shows that permeability in fracture-dominated formations are disproportionately sensitive to even small changes in effective stress. For example, observations from hydrocarbon reservoirs and aquifers demonstrate changes in production rates and water well levels with the passage of seismic waves (Steinbrugge \& Moran 1954; Voytov et al. 1972; Roeloffs 1998; Brodsky et al. 2003; Elkhoury et al. 2006). Transiting seismic waves only

\footnotetext{
* Now at Turkish Petroleum, 06530 Ankara, Turkey

${ }^{\dagger}$ Now at Geological and Planetary Science Division, California Institute of Technology, Pasadena, CA 91125, USA.
}

briefly (seconds to minutes) perturb the stress field, but the subsequent changes in permeability are typically more persistent (days to weeks; Rojstaczer \& Wolf 1992; Brodsky et al. 2003; Elkhoury et al. 2006; Manga et al. 2012; Xue et al. 2013), requiring a mechanism that contributes to this persistence. Analogously, direct evidence of permeability increase in response to anthropogenic fluid injection has also been observed-first in the form of pure fault-normal opening and then together with aseismic then seismic slip with the continuation of injection (Guglielmi et al. 2015). Interestingly, faults could be destabilized by injection-induced stress perturbations that are as small as $10^{-2} \mathrm{MPa}$ (McGarr et al. 2002), and by even smaller pressure changes imposed by the passage of seismic waves (10 ${ }^{-4} \mathrm{MPa}$; van der Elst \& Brodsky 2010; Manga et al. 2012). In such cases, the reduction in effective stress due to pore pressure perturbations results in shear reactivation - contributing to the permeability evolution of natural faults as also implied in reservoir stimulation treatments (Zoback et al. 2012; Mukuhira et al. 2017). 
The causative hydro-mechanical processes implicated in this complex fracture permeability response to fluid overpressures have been partly constrained by field- and laboratory-scale observations. Transiting oscillatory stresses following far-field earthquakes may remove and deposit colloidal material within the fracture network, leading to post-seismic changes in the fluid pressure field as observed in water wells (Brodsky et al. 2003; Elkhoury et al. 2006). This flux-driven particle mobilization model for dynamically enhanced fracture permeability has been found viable also based on observations from the pore pressure oscillation experiments (e.g. Roberts 2005; Elkhoury et al. 2011). Similarly, dualpermeability media may exhibit differential undrained poroelastic response, which suggests poromechanical origins for the enhanced fracture permeability (Faoro et al. 2012). Both mechanisms, that is particle mobilization and transient excess pressurization, predict enhanced permeability that is gradually recoverable with the removal of dynamic stresses. Conversely, for highly stressed fault damage zones, permeability increase may be the result of microfracturing that is driven by stress perturbations (Mitchell \& Faulkner 2008). This permits a crack closure-related recovery of the enhanced permeability with reduction in stresses - but not to the initial levels due to the microfracture damage that is permanent. Intriguingly, experimental dynamic stressing has only rarely been reported to result in decreased fracture permeability (e.g. Liu \& Manga 2009). This response was primarily attributed to redistribution of fine particles (effects of clogging and unclogging) and to the decrease in fracture aperture width resulting from this particle redistribution.

The proposed mechanisms for the dynamically enhanced fracture permeability (by Brodsky et al. 2003; Mitchell \& Faulkner 2008; Faoro et al. 2012) have recently been examined in a comprehensive set of pore pressure oscillation experiments (Candela et al. 2014). Microstructural investigation of the post-experimental fracture surfaces showed pore throats that are relatively cleared of the pre-existing fine particles closer to the preferential flow paths, without any evidence of microfracturing. Additionally, the magnitude of permeability increase and the rate of permeability recovery were reported to be affected by pore fluid chemistry, unlike the model suggested by Faoro et al. (2012). It was concluded that flux-driven particle mobilization may be the most probable mechanism, among the three proposed, dominating the fracture permeability increase in response to transient stresses at laboratory scale (Candela et al. 2014).

Meanwhile, a variety of shear-permeability experiments have explored static shear loading (monotonic rather than ephemeral loading) more than fluid injection, typically indicating dilation-induced permeability enhancement (e.g. Yeo et al. 1998; Chen et al. 2000; Gutierrez et al. 2000). Of the limited number of injection-induced permeability experiments, those involving strongly mated tensional fractures (Ye \& Ghassemi 2018) have registered strong permeability increase but are not necessarily representative of natural faults. Conversely, experiments with initially non-mated contacts show shear permeability reduction due to comminution and clogging of asperities (Asahina et al. 2019) or temporal permeability enhancement only during the slip phase (Nemoto et al. 2008). Furthermore, these experiments do not consider the permeability contribution of pressure-driven stimulation (absent shear deformation; Candela et al. 2014) in their analysis.

Previous studies have revealed complex interactions impacting permeability evolution during fracture reactivation; in that, shear slip deforms fracture walls through destruction and rearrangement of asperity contacts (Elsworth \& Goodman 1986; Im et al. 2019), which may result in permeability increases (e.g. Barton et al. 1985;
Wang et al. 2017) or decreases (e.g. Teufel 1987; Faoro et al. 2009). Among the controls over the sense of shear permeability evolution, more recently, compaction-induced fracture surface mating during pre-slip interseismic repose has been demonstrated (Im et al. 2018, 2019). Such recent advances in our understanding of shear permeability behavior has proven even more that laboratory testing of injection-induced fracture permeability evolution is needed to more accurately account for the physical interplay of processes in application to stimulation engineering (e.g. Mukuhira et al. 2017).

In the following, we explore hydraulic and mechanical behavior of fractures in response to both the separate and combined effects of pore pressure-dominant dynamic stressing and injection-induced shear deformation to account for their individual impacts. This is completed through the continuous measurement of fracture permeability evolution with stress and frictional shear where repeated fluid-pressure pulses are applied in flow-through experiments on pre-stressed fractures. The experiments are conducted over a range of spiked pore pressure magnitudes that are first incapable of reactivating the fractures but then indeed reactivate them. The results emphasize the systematically reversible and reproducible nature of dynamic fracture permeability evolution in response to the interplay between effective stress, fluid pressure, clogging and healing effects.

\section{METHODS}

To explore the impact of dynamic pressures and induced slip on permeability evolution, we concurrently monitor fracture permeability, shear stress and displacement responses to the pulses of successively incremented pore pressure and repeated pressure pulses of identical-magnitude. These are completed in well-constrained flowthrough experiments on saw-cut fractures in impermeable rock under recreated in situ stresses. The samples are confined within a triaxial pressure cell where the fractures are subjected to independently controlled confining stress, shear stress, and pore pressure (Fig. 1).

\subsection{Materials and sample preparation}

The experiments are conducted on functionally impermeable shales (Green River shale) and schists (Poorman Formation)representative of sedimentary reservoirs/seals and basement rocks, respectively (Goebel \& Brodsky 2018). The Eocene Green River shale is sampled from Grand Junction, Colorado from a sequence of organic-rich fine-grained rocks of lacustrine to fluvial-lacustrine origin (Self et al. 2010). Mineralogical characterization of these shale samples through X-ray diffraction indicates a high carbonate and low clay content (carbonate $\sim 52 \%$, tectosilicate $\sim 46 \%$, phyllosilicate $\sim 2 \%$; Fang et al. 2017). Matrix permeability (to Helium) is of the order of $10^{-23}$ to $10^{-22} \mathrm{~m}^{2}$ (Yildirim et al. 2019) which is in agreement with previous permeability measurements on other Green River shale samples (order of magnitude of $10^{-26}$ to $10^{-23} \mathrm{~m}^{2}$ to oil after brine saturation; Sandvik \& Mercer 1990). The Precambrian Poorman schist samples are recovered from a near-vertical borehole (kISMET-005) with collar at $1478 \mathrm{~m}$ below surface in the West Access Drift of the Sanford Underground Research Facility (SURF), Lead, South Dakota. These samples are from a sequence of well-banded, intensely folded and carbonate-bearing schists and phyllites (Caddey et al. 1991) with a mineralogical composition of $\sim 48 \%$ carbonate, $\sim 29 \%$ phyllosilicate, and $\sim 23 \%$ tectosilicate (Ye 


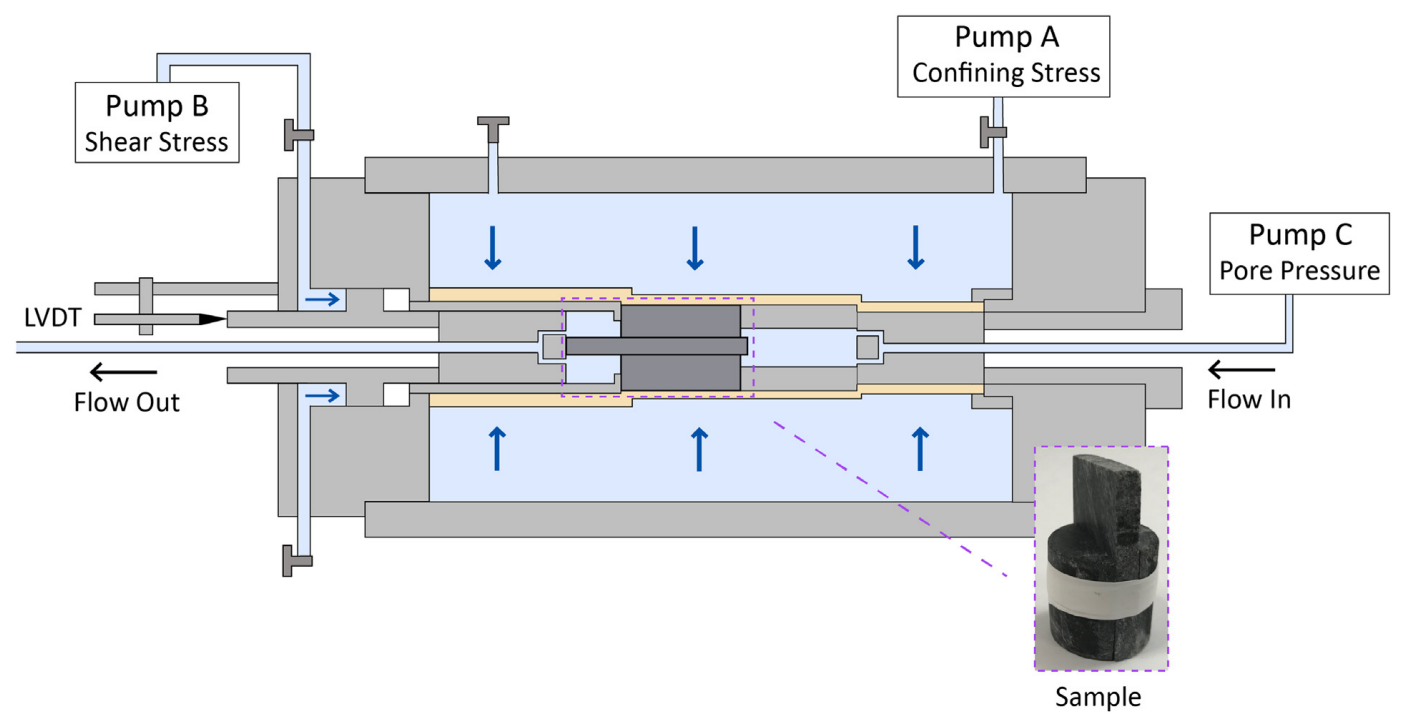

Figure 1. Schematic diagram illustrating the triaxial pressure cell and the double direct shear configuration of the sample. Dashed purple box outlines the sample in the cell. Each of the three servo-controlled pumps attached to the pressure cell is controlled independently.

et al. 2020). Null-recorded flow in samples identify matrix permeability in the sub- $10^{-20}$ to $10^{-21} \mathrm{~m}^{2}$ range.

We prepare three different Poorman schist samples and a single Green River shale sample to perform a total of four pore pressure stepping experiments (PS1, PS2, PS3, GRS1). Cylindrical core plugs from these rocks are split into two half-cylinders flanking a central prismatic coupon and sheared in double direct shear geometry (Figs 1 and 2). Fracture surfaces are flattened and smoothed using sand paper, then roughened with abrasive powder to create uniform roughness on each sample. The schists are roughened with \#320 grit ( $\sim 0.03 \mathrm{~mm}$ diameter) abrasive powder while the shales necessitate even rougher fracture surfaces (\#150 grit; 0.08 mm diameter) to allow measurable flow in the experiments. The prepared sample for each experiment is hydraulically isolated within a latex jacket and placed in the pressure cell.

\subsection{Experimental setup and procedure}

Each of the three servo pumps attached to the triaxial pressure cell applies independent pressures (Fig. 1). Fluid flow parameters for each pump (fluid volume, flow rate and pressure) are continuously tracked during the experiments. Pump A controls the confining pressure (normal stress) on the fractures which is kept constant at $3 \mathrm{MPa}$ throughout the entire experimental suite. The loading piston that advances the central rock coupon is driven by Pump B which applies shear-loading at a prescribed constant displacement rate and enables the monitoring of shear stress. A Linear Variable Differential Transformer (LVDT) mounted to the loading piston continuously records the shear offset of the sample. Pump C injects pore fluid through the fracture pair towards an outlet that is open to atmospheric pressure. The total effective permeability of the two fractures forming the double direct shear geometry (fracture permeability, k) is calculated based on Darcy's law (eq. 1) as

$k=\frac{\mu L}{A} \frac{Q}{P p}$,

where $L$ is the flow path length, $A$ is the cross sectional area of the sample perpendicular to the flow path, $Q$ is the flow rate, $P p$ is the differential (end-to-end) pore pressure across the sample and $\mu$ is the fluid viscosity of the de-ionized and de-aired water that is permeating this system $\left(8.9 \times 10^{-4} \mathrm{~Pa} \cdot \mathrm{s}\right)$. Considering the negligible matrix permeability of the samples, these calculations assume fluid flow to be completely through the fractures. This equation dictates direct proportionality of flow rate to fracture permeability provided constant $\mu, L, A$ and $P p$.

Designed as analogs of processes that are ubiquitously present in a spectrum of brittle regimes, these experiments are conducted at a constant normal stress of $3 \mathrm{MPa}$ which is within the range of in situ effective normal stresses that is estimated to be comparable to those acting on the optimally oriented fractures in overpressurized portions of shallow crustal depths (Fang et al. 2017). This is consistent with stresses on the in situ field scale fault-reactivation studies conducted by Guglielmi et al. (2015), as well as with a series of experiments equally exploring processes in brittle failure and friction (e.g. Fang et al. 2017; Im et al. 2018, 2019). We initiate each experiment by applying a confining stress of $3 \mathrm{MPa}$ that is retained constant throughout the experiment. Then, we initiate flow through the fractures by assigning an upstream pore pressure that discharges to atmospheric pressure downstream. Pore pressure differential $\left(P p_{0}\right)$ is selected aiming for a measurable flow rate that is sensitive to the anticipated permeability evolution driven by the pressure pulses. Initial fracture permeability is difficult to control and varies between samples (cubic dependence on aperture; Witherspoon et al. 1980) — hence, the initial flow rates are adjusted for sensitivity by controlling this pore pressure differential. Artifacts of fracture re-assembly (Im et al. 2018) are minimized by shearing the initial $4 \mathrm{~mm}$ offset with a constant shearing velocity of $10 \mu \mathrm{m} \mathrm{s}^{-1}$ to bed-in the sample. Following this, the sample is held at a constant confining stress over an extended period (Fig. 3a). These pre-slip hold periods in slide-hold-slide experiments are known to reset fracture permeability prior to reactivation (Im et al. 2018)-with resetting magnitudes sensitive to experimental parameters (e.g. Im et al. (2018) report varying fracture sealing rates between experiments on similar Westerly Granite samples with different initial fracture permeability.). Nevertheless, we estimate the minimum duration of the hold that would prime these fractures to range from minutes to hours based on results from the previous slide-holdslide experiments on Poorman schist (Yildirim et al. 2018) and 
(a)
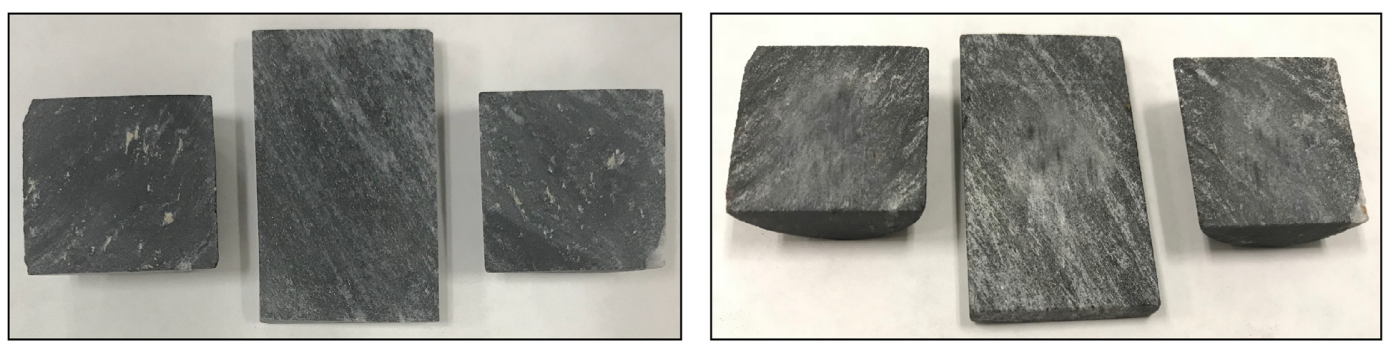

(b)
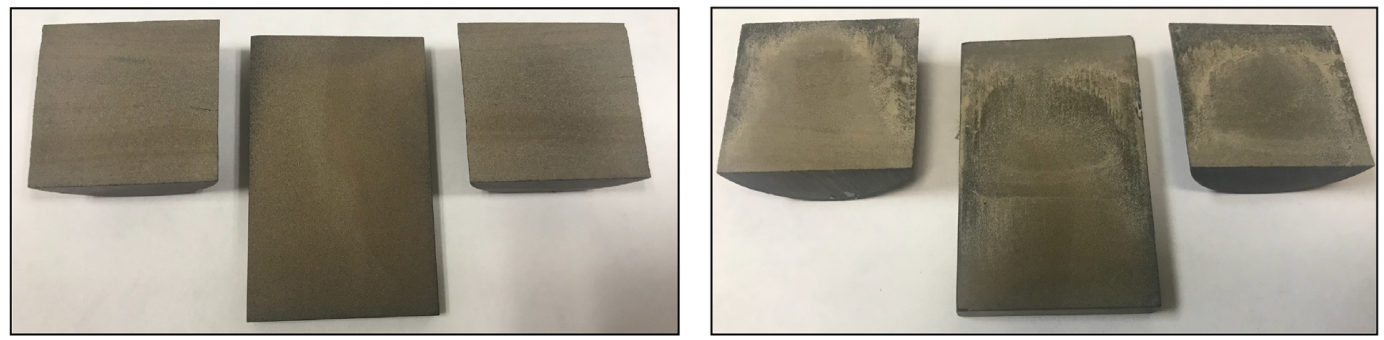

Figure 2. Fracture surfaces of the samples from (a) the Poorman schist and (b) the Green River shale, before (left-hand panel) and after (right-hand panel) the experiment. Poorman schist samples are from an earlier pressure stepping experiment (PS0 in Fig. S6). Note the almost uniform appearance of the Green River shale surfaces in contrast to the distinctly foliated Poorman schist surfaces. Sample size of the central rectangular prisms in $(\mathrm{a}$ and $\mathrm{b})$ is $\sim 0.004 \times 0.024 \times$ $0.038 \mathrm{~m}^{3}$.

Green River shale (Im et al. 2018) which were conducted with confining stresses similar to these experiments. The shortest hold period applied prior to pressure stepping is in PS2 $(\sim 8 \mathrm{hr})$ with longer durations in the other three experiments.

Pore pressure stepping begins following the hold period. Boxcar pulses of increased pore pressure are applied for $5 \mathrm{~s}$ each, with an intervening period of $120 \mathrm{~s}$ at the background pore pressure gradient $\left(P p_{0}\right)$ between successive pulses. Each pulse is applied at a peak pore pressure that is step-incremented relative to the preceding pulse $\left(\triangle P p=P p_{n}-P p_{n-1}\right.$; where $\mathrm{n}$ is the pulse number). Isolating each pressure step with a preceding and succeeding waiting time (hold) at the background pressure gradient allows the measurement of fracture permeability response to each individual pressure pulse. Fracture permeability following each pulse $\left(k_{n}\right)$ is recorded towards the end of the pulse-succeeding intervening hold, immediately before the next pressure pulse (Fig. 3b). $120 \mathrm{~s}$ is sufficiently long for a steady state flow regime to establish, absent storage effects, and short enough to not include the extensive chemical compaction/healing/sealing effects which are known to occur over minutes to hours, to days (Im et al. 2018), and to months (Yasuhara et al. 2004). For the final four pulses in each experiment, we stop step-increasing the pressure and simply apply the same pore pressure at each step. The final pulse is preceded by reapplying the shear stress (piston chamber pressure) in order to critically stress the fractures for an induced reactivation upon pore pressure perturbation. Following the pressure perturbation stage, we apply an additional hold and then directly reactivate the fractures through shear loading at constant velocity (slide) in order to evaluate the role of fracture healing and sealing on response (e.g. PS2 and PS3; see supplemented data for other cases).

Experiments in this study are designed to elucidate various aspects of fracture permeability response to dynamic pressure changes and flow-induced shear slip. Chronologically the last two experiments (PS3 and GRS1) are specifically targeted at resolving the response at the transition from the reactivation-absent to reactivationpresent pressure pulses. Therefore, experimental parameters are arranged considering fracture criticality and the protocol is slightly altered accordingly between the individual experiments. We observe that fractures in our experiments become non-critically stressed due to (presumed) slow creep during the extended hold periods before the pressure stepping. According to the results from Byerlee's experiments (1978), we expect a coefficient of sliding friction of at least $0.6-0.85$ for the shear failure of fractures. Additionally, fracture criticality at the conclusion of the pre-slip hold period in each experiment is evaluated with reference to the critical shear strength demonstrated by each fracture pair during the initial shear-in. Based on this evaluation, we reload shear stress to a near-critical level (i.e. close to the fractures' frictional strength) before initiating the pressure stepping in PS1, whereas the other experiments (PS2, PS3 and GRS1) are performed without this shear loading. Therefore, the fractures in PS1 become critically stressed and primed for slip prior to the pressure perturbations. Conversely, the fractures in PS2, PS3 and GRS1 remain non-critically stressed without the shear loading. Two of these experiments, PS3 and GRS1, are conducted with relatively lower initial pore pressure $\left(P p_{1}\right)$ and smaller pressure increments $(\triangle P p)$ than PS1 and PS2; therefore, injection induces shear reactivation only after multiple pulses - allowing a separate analysis of shear-absent and shear-associated events. Overall, the total number of pore pressure pulses and their magnitudes $(P p)$ are varied between experiments. The reason for this is twofold. The first is scientific - to ensure that the transition from no-reactivation to reactivation is captured. And the second is pragmatic - to complete the experiments with a single filling of the pump chamber, where refilling then restarting disrupts the continuity of the effective stress regime and potentially invalidates the experiment. Details of each experiment are displayed in Table $\mathrm{S} 1$ in the supporting information.

\section{RESULTS}

We present detailed results from four pore pressure stepping experiments probing the separate and combined effects of dynamic stressing and injection-induced shear reactivation on fracture permeability and friction evolution (Fig. 4). After equilibrating the fractures with a long hold period, each experiment proceeds by applying successive pulses of step-increased pore pressure, followed by four pulses of identical-pressure. Optionally, a final hold 
(a)
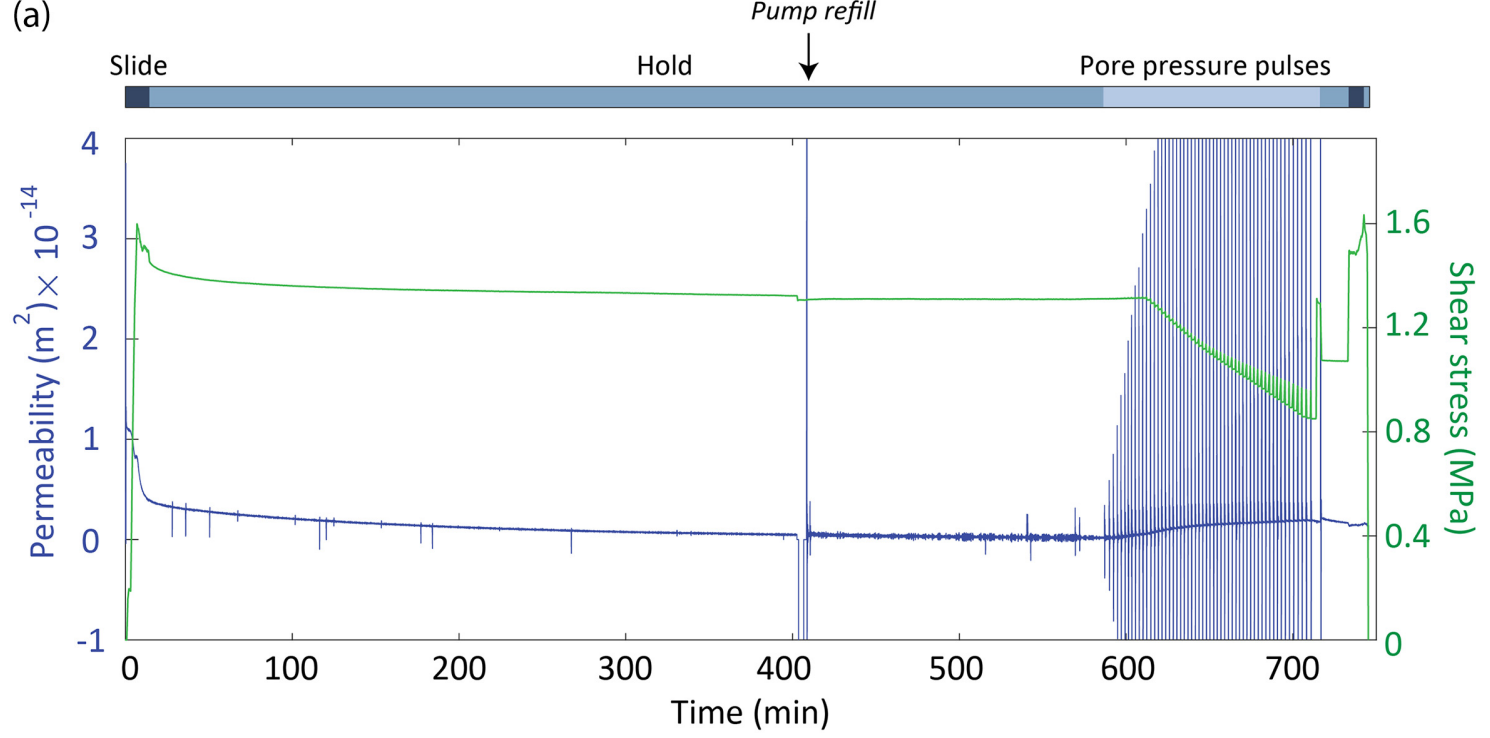

(b)

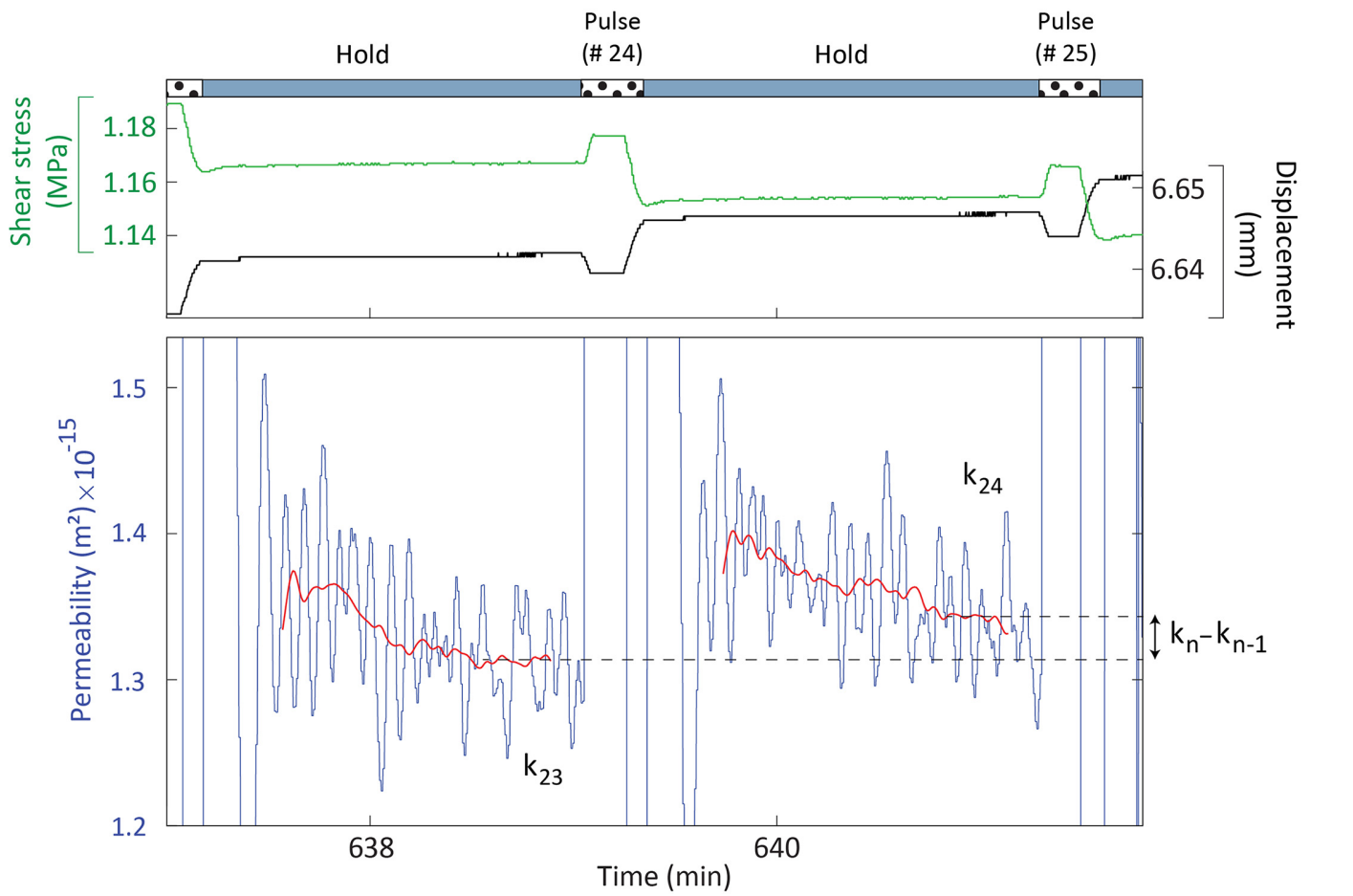

Figure 3. (a) Full record of the complete multistage experiment performed in PS3. During the pressure stepping, differential pore pressure is progressively increased with per-pulse increments of $30 \mathrm{kPa}$ from $P p_{1}=250 \mathrm{kPa}$ to $P p_{53}=1810 \mathrm{kPa}$. Details of the procedure and the experimental parameters in all experiments are shown in Table S1. (b) Zoomed-in view to a few pulses of the pressure stepping portion of the same experiment. Note that the displacements are driven only by the pore pressure pulses (i.e. they are 'induced' slip). Red curve represents the running average of the measured fracture permeability (blue curve). Dashed black lines mark the approximate permeability readings for pulses $P p_{23}$ and $P p_{24}$. Here, $k_{24}-k_{23}$ gives the permeability increment due to $P p_{24}$.

period and shear offset follow dynamic stressing. These experiments recover a broad range of hydraulic and mechanical responses to pulsed pore pressures which become capable of inducing fracture reactivation with the progressive increments in magnitude.

Temporal fracture permeability evolution in response to pore pressure pulses, holds, and slides in experiments GRS1, PS3, PS2 and PS1 are displayed in Figs 4(a)-(d). Additionally, concurrent displacement response at the transition from the reactivation-absent to reactivating pressure pulses in GRS1 and PS3, as well as the shear strength and friction evolution in PS3 are displayed as insets in Figs 4(a) and (b). Since permeability evolution is evaluated at a constant normal stress and a constant background pore pressure, we consider shear strength evolution as representative of the evolution of friction in each pressure stepping experiment. The complete results are provided in the supporting information, including the calculated friction coefficient evolution (Figs S1-S4). 

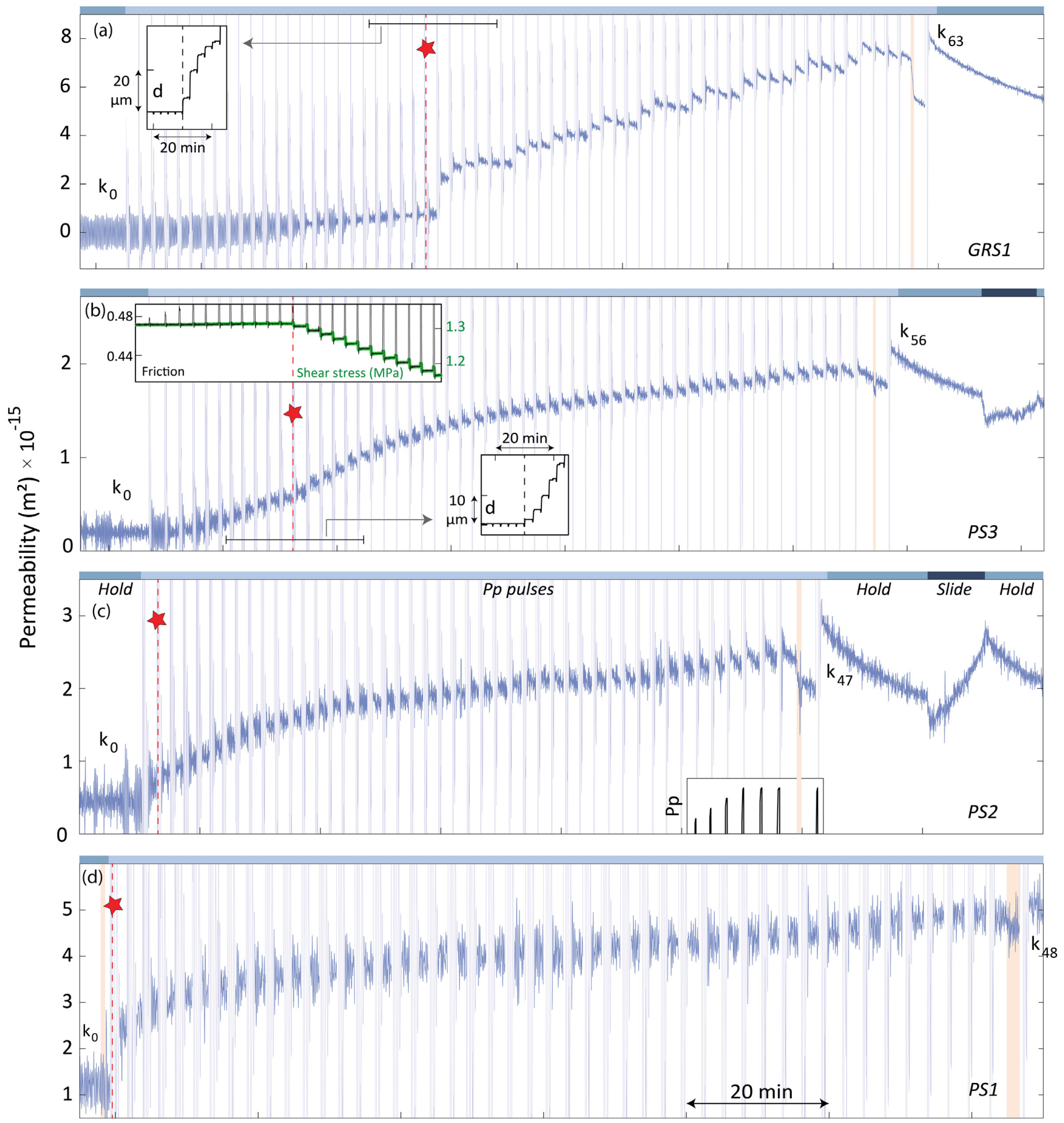

Time

Figure 4. Fracture permeability evolution due to dynamic pressure perturbations and the additional hold and slide in experiments with samples from the Green River shale (GRS1; panel a) and the Poorman schist (PS3, PS2, PS1; panels b, c, d). Dashed red lines with red stars mark the initiation of shear slip resulting from the injection at increased pore pressure. Displacement responses to stress perturbations at the moment shear reactivation starts in GRS1 and PS3 are shown in respective insets in (a and b). Friction and shear stress evolution in PS3 is shown in the second inset in (b). Inset in (c) shows a representative portion of the pore pressure, which is incremented in successive pulses before applied at a constant magnitude during the final four pulses (the final pulse in the critically stressed state). Shear loading is marked by orange shading (also in Fig. 8).

\subsection{Permeability enhancement and step-increasing pore pressure pulses}

These experiments show that fracture permeability increases in response to step-increased pore pressure. Permeability increase peaks by the time the applied overpressurization finalizes, which is followed by a gradual decrease in permeability during the pulsesucceeding hold period. These decreases in the observed permeability are gradual but become accelerated through the higher-pressure 

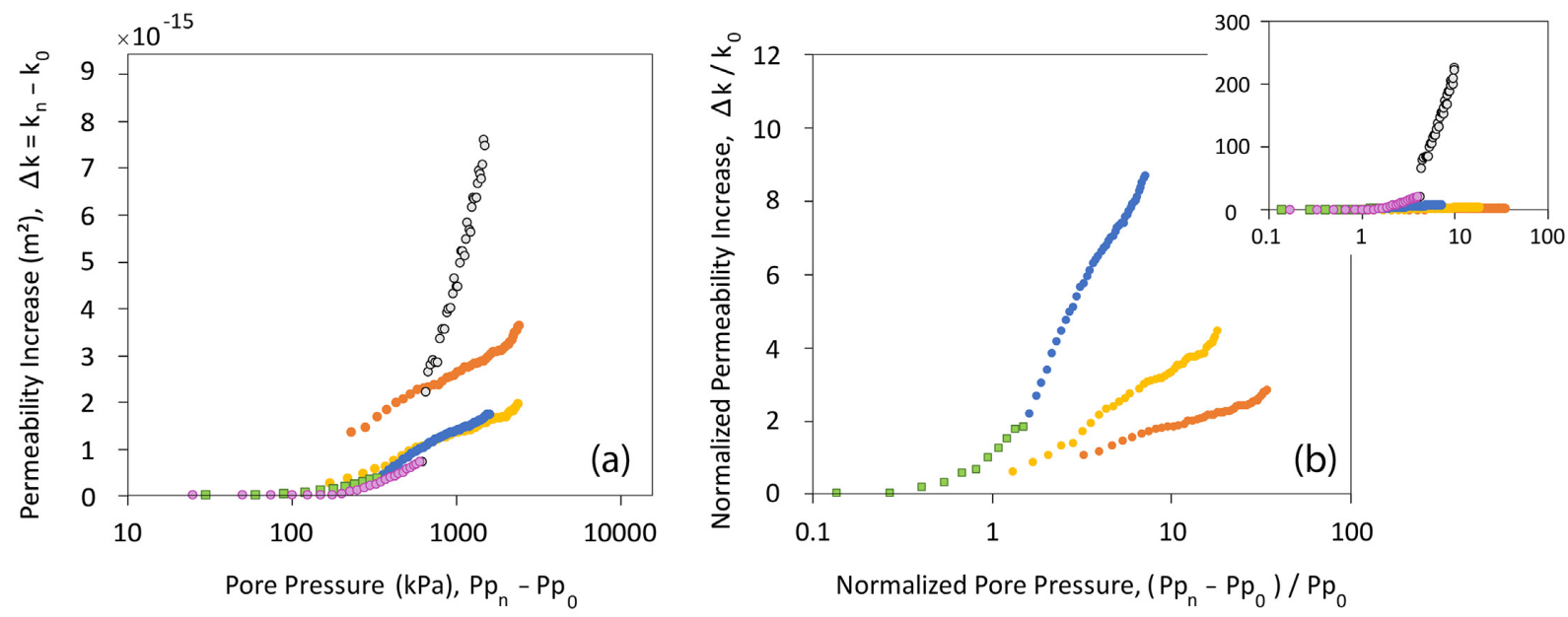

\begin{tabular}{|c|c|c|c|c|}
\hline No slip: & GRS1 & $\square P S 3$ & & \\
\hline Slip-associated: & O GRS1 & - PS3 & PS2 & PS1 \\
\hline
\end{tabular}

Figure 5. (a) Absolute permeability increase versus pore pressure increase and (b) normalized permeability increase versus normalized pore pressure increase. Inset in (b) shows the normalized permeability increase in GRS1 together with the results from PS1, PS2 and PS3. The same color scheme corresponding to denoted experiments applies through Figs 6 and 7.

pulses. Pump over- and undershoots during pulsing, together with fluid storage effects, prevent permeability from being accurately determined during dynamic stressing. Nevertheless, permeability changes are accurately interpreted from the steady state conditions once these effects disappear (Fig. 4).

Shear slips are induced by the elevated pore pressure in the early phases of pulsing in PS1 and PS2 (red stars in Figs 4d and c, respectively) and only after multiple pulses in PS3 and GRS1 (Figs 4b and a). Therefore, the early stages of the latter two experiments showcase the response to transient stresses that are incapable of inducing shear deformation (as in Elkhoury et al. 2011; Candela et al. 2014, 2015). Shear reactivation response is immediate at stress perturbation and is followed by a reduced creep velocity. Injection-induced shear offsets are typically a few microns in these experiments. Spikes in the shear stress and displacement responses to higher-pressure pulses are not associated with the actual fracture slip (Figs S1-S4). These are artifacts resulting from the upstream pressure pushing the loading piston backward.

We report that all experiments result in a major increase in fracture permeability with dynamic stress perturbations, both in the absence and presence of injection-induced shear deformation. Stepincreases in pore pressure perturbs fracture permeability starting with the seventh pulse in experiment GRS1 (Fig. 4a). Permeability increases steadily with the uniform permeability increments of $\sim 0.5 \times 10^{-16} \mathrm{~m}^{2}$ (normal dilation only) in response to the consecutive pressure increments of $25 \mathrm{kPa}$. By the time that the injection starts inducing slip on the fracture (with $P p_{25}$ ), permeability has already been enhanced to $\sim 7.5 \times 10^{-16} \mathrm{~m}^{2}$ from an initial value $\left(k_{0}\right)$ of $\sim 3.4 \times 10^{-17} \mathrm{~m}^{2}$. This represents a cumulative permeability increase of $\sim 7.16 \times 10^{-16} \mathrm{~m}^{2}$ as a result of a total transient pore pressure change of $0.6 \mathrm{MPa}$ over the background pressure gradient. Similarly, fracture permeability starts increasing with the second pressure pulse in PS3 (Fig. 4b). The total transient pressure change of $0.33 \mathrm{MPa}$ throughout the first 11 pulses derives a permeability increase of $\sim 3.7 \times 10^{-16} \mathrm{~m}^{2}$, from an initial value of $\sim 2.0 \times 10^{-16}$ to $\sim 5.7 \times 10^{-16} \mathrm{~m}^{2}$, before the first induced shear reactivation with $P p_{12}$. Permeability continues to increase in a positive correlation with the applied pressure magnitude even after the initiation of injection-induced shear slip in both experiments. However, a major slope change in fracture permeability enhancement $(\mathrm{d} k / \mathrm{d} p)$ is remarkable with the start of induced slip.

Shear reactivation is induced in the early phases of the other two experiments on Poorman schist. In PS1, shear stress is reloaded close to the frictional strength of the fracture before initiating the pulses. Then, the first pressure pulse is applied as the maximum pore pressure increment compared to the rest of the pulses in the experiment. This results in a strong shear slip $(\sim 0.021 \mathrm{~mm})$ on the critically stressed fracture, with permeability doubling over the initial permeability (from $\sim 1.3 \times 10^{-15}$ to $\sim 2.6 \times 10^{-15} \mathrm{~m}^{2}$; Fig. $4 \mathrm{~d}$ ). This maximum per-pulse permeability increment represents $\sim 37 \%$ of the cumulative permeability increase achieved in this experiment. In PS2, shear slip is induced starting with the second pulse (Fig. 4c). As the only pressure pulse that does not induce reactivation, the first pulse enhances permeability from $\sim 4.4 \times 10^{-16}$ to $\sim 7.0 \times 10^{-16} \mathrm{~m}^{2}$, resulting in a permeability increase of $\sim 2.6 \times 10^{-16} \mathrm{~m}^{2}$ for a stress perturbation of $0.17 \mathrm{MPa}$. With smaller pulse pressure increments in the remainder of the experiment $(0.05 \mathrm{MPa})$, this permeability increase remains as the largest in PS2.

Absolute and normalized permeability enhancements $(\Delta k=$ $k_{n}-k_{0}$ and $\left.\Delta k / k_{0}\right)$ in all four experiments are shown in Figs 5(a) and (b). Fracture permeability generally increases with step-increased pore pressure in successive pulses. This increase is by up to about an order of magnitude in the experiments on Poorman schist (from $\sim 2.0 \times 10^{-16}$ to $\sim 1.9 \times 10^{-15} \mathrm{~m}^{2}$ in PS3) and by more than two orders of magnitude in GRS1 (from $\sim 3.4 \times 10^{-17}$ to $\sim 7.5 \times 10^{-15} \mathrm{~m}^{2}$ ). Total equivalent hydraulic aperture increase of a single fracture in each experiment is 3.4, 3.2 and 3.6 $\mu \mathrm{m}$ in PS1-3, and $9.1 \mu \mathrm{m}$, in GRS1 (using cubic law; Witherspoon et al. 1980; Im et al. 2018).

\subsection{Permeability response to pressure pulses in the absence and presence of injection-induced shear reactivation}

Fig. 6 shows a detailed analysis of the fracture permeability response in GRS1 and PS3 to pore pressure pulses that are first incapable and 

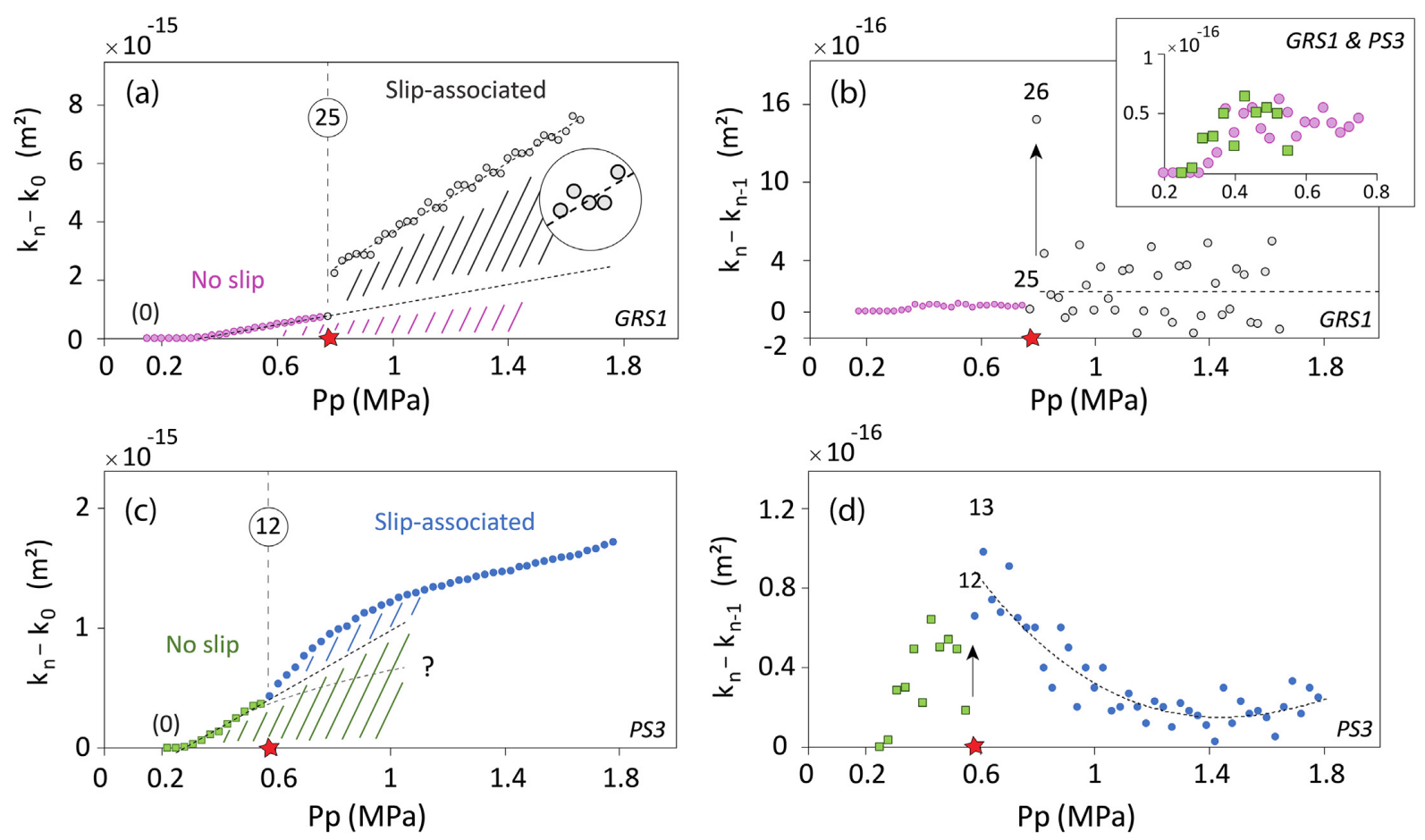

Figure 6. Cumulative permeability increase $\left(k_{n}-k_{0}\right.$; a and c) is accelerated by the increase in per-pulse permeability increments $\left(k_{n}-k_{n-1} ; \mathrm{b}\right.$ and d) following the initiation of injection-induced shear slip (at $P p_{25}$ in GRS1 and $P p_{12}$ in PS3). Note the slope change in permeability increase versus pore pressure gradient both in (a) GRS1 and (c) PS3. Inset in (b) shows the shear-absent permeability increments in the two experiments together $\left(\triangle P p_{G R S 1}=25 \mathrm{kPa}\right.$ and $\left.\triangle P p_{P S 3}=30 \mathrm{kPa}\right)$. Dashed curves are fitted to data except for the one in (b), where the scattered increments do not represent a clear trend for a fit. The horizontal line in (b) denotes the mean per-pulse permeability contribution $\left(\sim 1.5 \times 10^{-16} \mathrm{~m}^{2}\right)$ predicted by the shear-associated trendline in (a). Permeability behavior under 'pure' dynamic normal stress perturbations, absent shear reactivation, is not clear beyond our experimental suite. Such behavior may be the continuation of the fitted linear trends in (a) and (c) or may adopt any other trend (e.g. logarithmic increase) as also outlined in (c). An exemplary portion of the shear-associated permeability increase in GRS1 is shown in zoomed-in view in (a). Similar analysis of the results from PS1 and PS2 are included in the supporting information (Fig. S5).

then capable of inducing shear slip. In both experiments, permeability increases with pressure regardless of the association of slip. However, initiation of the injection-induced shear slip results in a slope change in the permeability increase $(\mathrm{d} k / \mathrm{d} p$, Figs $6 \mathrm{a}$ and $\mathrm{c})$. Fracture permeability enhancement is significantly accelerated by an increase in the per-pulse permeability increments, particularly following the second shear-associated pressure pulse in both experiments (Figs $6 \mathrm{~b}$ and d).

Both in PS3 and GRS1, the second slip-associated pulse induces a larger shear offset than the first one (e.g. $d_{12}=\sim 1 \mu \mathrm{m}$ and $d_{13}=$ $\sim 4 \mu \mathrm{m}$ in PS3; Fig. $4 \mathrm{~b}$ inset), also producing the larger permeability increase. In fact, the maximum permeability increment occurs with the second shear reactivation in both experiments. The first shear-associated pulse in PS3 $\left(P p_{12}\right)$ induces a larger permeability enhancement than the previous pulses, whereas no such response is observed in GRS1 $\left(P p_{25}\right)$. In GRS1, the second induced slip $\left(P p_{26}\right)$ results in a large step-wise increase in permeability from $\sim 7.6 \times$ $10^{-16}$ to $\sim 2.2 \times 10^{-15} \mathrm{~m}^{2}$.

Intriguingly, experiments exhibit differences in the permeability evolution in response to dynamic pressures and its coupling with the induced shear reactivation. The cumulative permeability increase follows a linear trend in GRS1 both before and after the initiation of shear slip, yet with a change of slope in permeability increase with pressure (Figs 6a and b). Permeability increases linearly also in the shear-absent portion of PS3 but it adopts a polynomial trend when dynamic stresses are coupled with shear reactivation (Fig. 6c). The variation in per-pulse permeability response to each incremented pore pressure is comparable between the pre-induced-slip portions of the two experiments (PS3 and GRS1; Fig. 6b inset), with the response to the first few pulses being smaller than the followings in both of them. In PS3, the slip-inducing pore pressures result in progressively smaller permeability increments with each pulse. These shear-associated permeability increments are always positive but decline in successive magnitude (Fig. 6d), which results in a slowing but continuous increase of permeability with the sequence of pressure perturbations (Fig. 6c). Similar shear-associated permeability behavior is observed in the other PS experiments (Fig. S5). In contrast, permeability increments become much more scattered in GRS1 without a clear decreasing trend. Shear-driven spontaneous incorporation of negative- and null-changes between the positive permeability increments leads to an intermittency in the cumulative permeability increase (Figs 6a and b). Nevertheless, permeability increases following a linear trend even with the intermittency. Since permeability generally increases with the applied pulses of the stepincreasing pore pressure differential, any correlation (or lack of it) between the applied changes in pore pressure and the resultant permeability increments is also reflected in the relationship between the initial permeability $\left(k_{n-1}\right)$ and the per-pulse permeability change $\left(k_{n}-k_{n-1}\right.$, Fig. 7).

The anticipated contribution of the 'pure' dynamic stresses (absent shear deformation) is outlined in the extrapolations of Figs 6(a) and (c). Nevertheless, we note that the described dynamic permeability behavior in the absence of shear slip is valid only for the range of pore pressures explored. For example, projection of the 


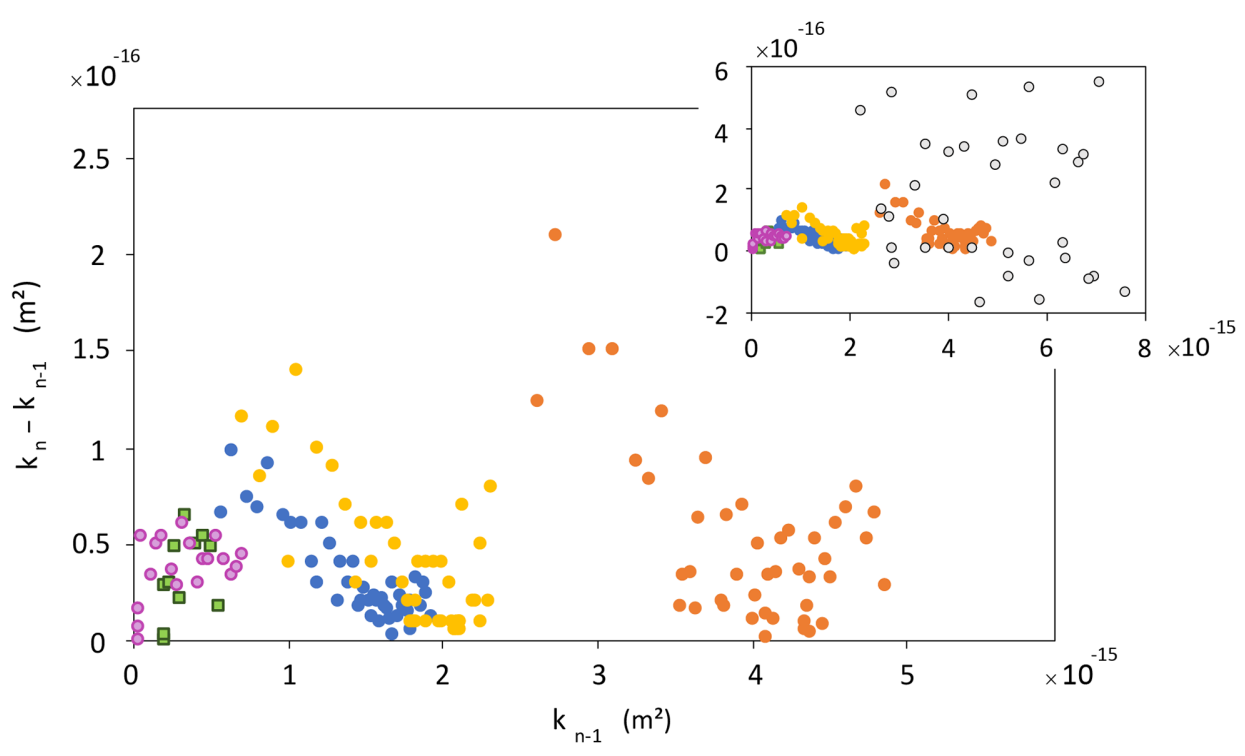

Figure 7. Initial permeability $\left(k_{n-1}\right)$ versus permeability change $\left(k_{n}-k_{n-1}\right)$ for pulses in all experiments. Only the response to the pulses of uniformly incremented pressure are plotted; that is, response to $P p_{1}$ in PS2 and PS1 are excluded. Inset shows the response in GRS1 after the start of shear slip (pulses $P p_{25}$ and $P p_{26}$ are excluded), together with the results in the main panel. Pore pressure increments are different for each experiment (see Table S1).

no-slip linear permeability increase in PS3 exceeds the observed cumulative permeability increase, which is unrealistic (Fig. 6c). The behavior over prolonged dynamic stressing is not clear beyond our experimental data.

\subsection{Permeability response to repeated uniform-magnitude pore pressure pulses}

The highest-pressure pulse in each experiment is repeated a total of four times, following the sequence of successively incremented pore pressures (e.g. $P p_{53} \sim P p_{56}$ of experiment PS3 in Fig. 8). Fractures are near-critically stressed through shear-loading only before the final repeated pulse. This set of pulses demonstrates that reapplication of a pulse at the same peak pressure does not induce any further displacement, unless the fractures are critically stressed before the repeated pressurization. The critically stressed fractures show substantial shear slip upon application of the final pulse. Comparably, when fractures are not reactivated by the pulsed-injection, permeability shows no further enhancement and attains similar values in response to repeated pulsing at the same pressure (Figs 8b and d). In contrast, permeability is enhanced further by the slipinducing fourth pulse - by up to $\sim 45 \%$ in PS2 (from $\sim 2.0 \times 10^{-15}$ to $\sim 2.9 \times 10^{-15} \mathrm{~m}^{2}$ ) and $\sim 47 \%$ in GRS1 (from $\sim 5.3 \times 10^{-15}$ to $\sim 7.8 \times 10^{-15} \mathrm{~m}^{2}$ ).

Enhanced permeability response to the first application of the pulse is perfectly reproduced with the following two reapplications in all experiments with Poorman schist (note the green, orange and blue markers stacked at $k_{n} / k_{N-3}=1$ for these three consecutive pulses in Fig. 8d). This reproducibility appears imperfect in GRS1, although the second and the third application of the same pulse recovers $98 \%$ and $97 \%$ of the enhanced permeability that is achieved due to the first time (purple circles in Fig. 8d). The imperfect perpulse permeability reproduction in GRS1 may be due to the fluctuations in permeability increments in GRS1, in contrast to the more consistent increment trend in the PS experiments (Figs $6 \mathrm{~b}$ and d).

\subsection{Permeability response to direct shear}

Hold periods that are applied after the dynamic stressing experiments typically result in a continuous decline in permeability similar to those observed during the prolonged hold periods prior to the experiments. During the $\sim 15$ min hold periods in PS2 and PS3, permeability declines from $\sim 2.9 \times 10^{-15}$ to $\sim 1.9 \times 10^{-15} \mathrm{~m}^{2}$ ( $\sim 34 \%)$ and from $\sim 2.1 \times 10^{-15}$ to $\sim 1.7 \times 10^{-15} \mathrm{~m}^{2}(\sim 19 \%)$, respectively. Then, the direct fracture reactivation following the final hold enhances permeability significantly in PS2 (from $\sim 1.9 \times 10^{-15}$ to $\sim 2.8 \times 10^{-15} \mathrm{~m}^{2}$; Fig. $\left.4 \mathrm{c}\right)$ and results in a slight permeability increase in PS3 (Fig. 4b).

\section{DISCUSSION}

We observe a rich range of fracture permeability and friction responses throughout these reactivation and hold experiments. Fracture permeability decreases during hold periods and increases with increasing pore pressure and shear deformation. We codify these responses relative to mechanistic controls.

\subsection{Healing and sealing}

In our experiments, fractures are subject to long hold periods, representing interseismic repose in the seismic cycle, prior to the application of incremented pore pressure pulses. The gradual permeability reductions observed during hold (sealing ) are commensurate with those observed in natural systems (Elkhoury et al. 2006; Xue et al. 2013) - albeit with an accelerated rate for the experimental observations. The slow and continuous permeability decrease observed during the long hold periods, both pre- and post-stimulation, implies that chemo-mechanical compaction may be a dominant mechanism. With insignificant rates of quartz dissolution at room temperature (Dove \& Crerar 1990), such sealing behavior may primarily be driven by stress corrosion (Yasuhara \& Elsworth 2008) which may be contributed by clogging of flow paths, both by precipitation of 

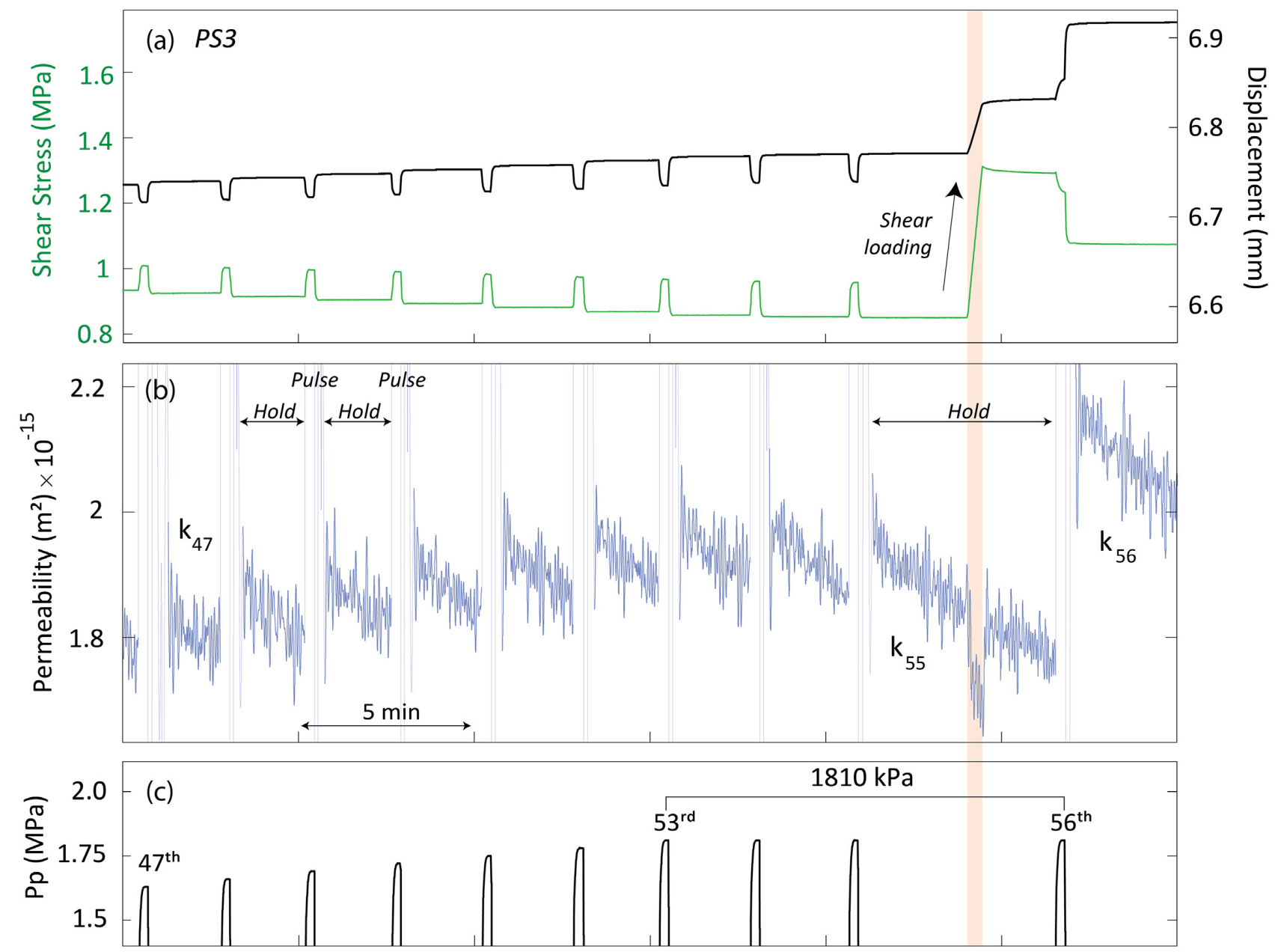

Time

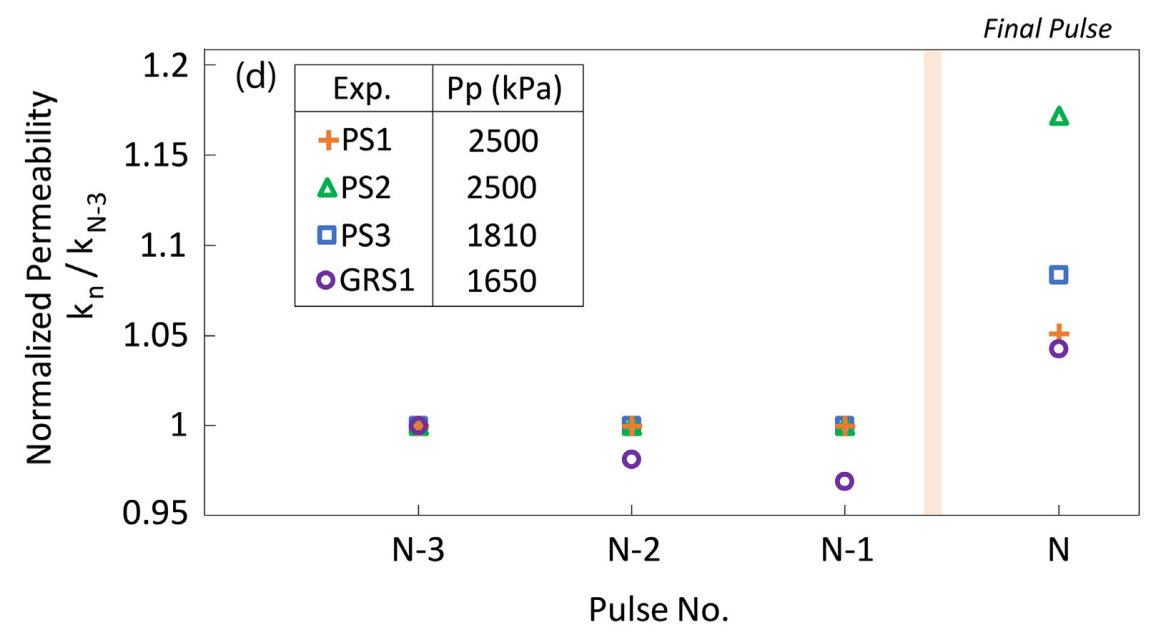

Figure 8. Permeability-friction response to application of the repeated uniform-magnitude pressure pulses. (a-c) Evolution of shear stress/displacement and permeability in response to pore pressure changes in PS3. Successively incremented pressure $\left(P p_{1}-P p_{53}\right.$ in PS3) is applied at constant magnitude through the final four pulses $\left(P p_{53}-P p_{56}\right)$. Different from the preceding three pulses, the final pulse is applied to the critically stressed fractures. (d) Permeability that is normalized by the response to the first application of the repeated uniform-magnitude pulses in each experiment $\left(k_{N-3}\right.$, where $N$ is the total number of pulses in an experiment). The displacement at the time of shear loading is an artificial response resulting from the compaction of experimental material with loading. The false step-decrease in permeability during shear loading (and during slides in Fig. 4) is also an artifact resulting from the reduction in upstream reservoir volume due to the volume of sample intruding into the inlet chamber ( $\operatorname{Im}$ et al. 2018). 
minerals following the pressure solution at asperity contacts (Yasuhara et al. 2004) and by the slow accumulation of mobilized fines at the pore throats. The effect of clogging by particle mobilization during the hold periods may be inferred from the permeability behavior during the initial shear-in. Comminuted wear products released into the fracture network produce an exaggerated clogging response during the initial shear offset, resulting in a rapid permeability reduction within minutes (Fig. 3a). Clogging may also contribute to sealing during the hold following the shear offset, though at a much slower rate in contrast to its effect during the shear-in.

\subsection{Mechanisms of permeability enhancement}

Pre-slip frictional healing and sealing of fractures over repose periods has been demonstrated to be essential in defining the fracture permeability response following reactivation (Im et al. 2018). Our experiments show that pulsed-injection driven permeability enhancement is also strongly influenced by sealing. When shear slip is not associated, the enhanced permeability resulting from a given pressure pulse appears of a uniform magnitude that does not vary with repeated pulsing at the same pressure (Fig. 8). If we assume that the permeability enhancement resulting from the pulse scales with the applied pore pressure, the permeability increment due to a single pulse is accordingly dependent on the amount of the fracture sealing prior to the application of the pulse. Fig. 8(b) implies that, for pulses of the same pressure magnitude, the more the fracture seals during the pre-pulse hold, the higher the permeability increment is resulting from the following pulse - this is necessary to reach to the pre-ordained enhanced permeability. This demonstrates the dependency of pressure pulse-driven permeability evolution on the pre-stimulation sealing.

The latest experimental studies suggest that dynamic permeability enhancement may be primarily dominated by a flow-driven mechanism by which fine particles are mobilized and removed from the fracture network (Elkhoury et al. 2011; Candela et al. 2014, 2015). This model requires a strong dependency of the fracture permeability behavior to the budget of particles blocking the fracture throats. In principle, the availability of fines in the flow conduits is a prerequisite to allow remobilization, and the potential unclogging of fracture. Previous experimental observations reinforcing the unclogging hypothesis have been made exploring the response through changes in pore pressure amplitude that were as large as $0.5 \mathrm{MPa}$, typically without involvement of shear deformation (Candela et al. 2014, 2015). In this study, we further probe response to a range of pore pressure magnitudes which are first incapable of reactivating the fractures but then progress through reactivation. This allows quantification of the relative effects of the absence and presence of shear reactivation on dynamic fracture permeability.

\subsubsection{Permeability increase during 'pure' pressure pulses}

In the absence of shear deformation, cumulative permeability increase scales linearly with peak pore pressure, with a goodness of fit $R^{2}=0.97$ in PS3 and $R^{2}=0.99$ in GRS1 (Figs 6a and c). Initially, the first several pulses result in progressively larger permeability increments, enhancing permeability more efficiently with each pulse, before pulse efficiency stabilizes above a threshold peak pressure. The remainder of the shear-absent permeability increments in response to uniform increases in pressure are within a certain range of magnitudes in each experiment, regardless of whether the pressure change is applied at a relatively lower or higher pressure (inset in
Fig. 6b). This is perhaps more apparent in GRS1, where the applied range of pore pressure magnitude is approximately double the range in PS3, therefore allowing an extended observation of permeability behavior before shear deformation is induced. Per the particle mobilization concept, where the key control enhancing permeability is the flow-removal of blockages, greater permeability increase would be expected from the larger pre-existing permeability in contrast to a relatively smaller pre-existing permeability value (Elkhoury et al. 2011). The initial portion of the shear-absent permeability increase in our experiments may conform with this idea. Nevertheless, the later per-pulse permeability increments are unequivocally independent of the initial permeability in GRS1 (note the pink markers in Fig. 7), which results in a linear scaling of the cumulative permeability increase to the peak pore pressure, unlike the exponential scaling observed by Elkhoury et al. (2011) and Candela et al. (2015). Additionally, the elevated efficiency of the first stress perturbation in increasing permeability, as reported from the experiments by Candela et al. (2015), is not observed in our experiments. A similar observation was recently noted also by Shokouhi et al. (2019).

Our experiments show that, whether shear-associated or not, perpulse fracture permeability enhancement is ameliorated with fracture sealing during the pulse-intervening hold period. This represents a single cycle of permeability enhancement (dilation) and its amelioration (healing and sealing) before repeating with application of the next pulse-and-hold pair (Fig. 3b). This reversibility of the sense of fracture permeability is systematic throughout the experiments. Furthermore, the response to the identical pressure pulses shows that the permeability decrease during fracture sealing is almost fully recoverable with the following fracture breaching, even absent shear slip and in pulse recurrence intervals of a few minutes (Fig. 8b). These characteristics of the dynamic permeability cycles are typical of the rate-and-state frictional healing in response to stress/velocity perturbations (e.g. Segall \& Rice 1995), rather than of the clogging/unclogging process (e.g. Elkhoury et al. 2011; Candela et al. 2015). In particular, considering clogging/unclogging as the sole contributing process to permeability enhancement leaves uncertain the source of consistent and fast-generated wear material in the absence of shear slip, especially during the identical pressure pulses applied in our experiments. Usefully, frictional healing provides a systematic, reversible, and reproducible response to stress/velocity perturbations that is related to the evolution of the physical state of contact surfaces (Marone 1998). However, the mechanism of pulse-driven frictional rupture and its linkage to sealbreaching remain unclear although a reversible and fast-responding mechanism is implied. Furthermore, it should be noted that not all observations of the permeability evolution in these experiments can be fully explained as a rate-and-state friction type behavior. For example, it is apparent that comminution and wear-product-clogging dominate the initial shear-in and may also aid fracture sealing during the hold periods. Indeed, it is possible that its reverse process (i.e. unclogging) may be one of the contributors of the observed pulse-driven permeability increase - despite some of our observations that diverge from the conclusions of Elkhoury et al. (2011) and Candela et al. (2015).

\subsubsection{Fracture permeability contribution of shear deformation}

Fracture permeability increases systematically upon stress perturbations, scaling with the peak pore pressure, as also observed elsewhere (Elkhoury et al. 2011; Candela et al. 2014, 2015). Here, we further show that this permeability enhancement can be promoted significantly by shear slip, based on the observations that 
(i) initiation of shear reactivation of fractures results in a slope change in permeability enhancement ( $\mathrm{d} k / \mathrm{d} p$, Fig. 6), and that (ii) permeability is further enhanced only by the slip-inducing pulse out of the set of four identical-pressure pulses (Fig. 8). Postexperimental observations of wear and asperity plowing on the fracture surfaces provide evidence for asperity degradation and production of fine particles (Fig. 2), as expected due to the shear deformation of fractures.

Both in PS3 and GRS1, the second shear-associated pressure pulse results in a much larger displacement and permeability increment than the first shear-associated pulse. This may be possible if the first induced slip did not occur completely over the contact. In our configuration, shear stress may have been accumulated at the edge of the contact rather than being uniformly distributed over the contact surface. Therefore, it is possible that the first pulse induces shear slip only on the stress accumulated portion of the fracture surface. Another explanation may be that the first slip distance $(\sim 1 \mu \mathrm{m}$ for PS3 and $\sim 6 \mu \mathrm{m}$ for GRS1) may not be large enough to fully separate the real area of the asperity contact that was enlarged during the $>8 \mathrm{hr}$ of hold. In rate-and-state friction, the friction change occurs over a critical distance of tens of microns (Marone 1998; Baumberger \& Caroli 2006).

We observe that permeability enhancement in the presence of injection-induced shear reactivation adopts two distinct behavior. Permeability increases (i) continuously with each incremented pore pressure in PS3 (and in all PS experiments) and (ii) discretely in the form of positive permeability increments followed by negativeand null-changes in GRS1 (Fig. 6). The continuous increase trend in permeability is also apparent in response to direct shearing and has previously been observed in studies on shear dilation (Niemeijer et al. 2008, 2010; Chen et al. 2015; in a similar experimental configuration in Im et al. 2018, 2019; and during injection-induced dynamic slip in Nemoto et al. 2008). Conversely, the variations in per-pulse permeability changes in GRS1 may be indicative of the involvement of a non-systematic stimulation process at interplay with shear dilation. These may be the overprints of flux-driven mobilization of particles as this non-systematic behavior is manifest especially after the initiation of shear reactivation, when the comminution products of the degrading asperities are incorporated into the material budget. In that case, the degree of smoothness of the cumulative permeability increase curve would be controlled by the balance between the number of wear particles produced with perpulse shear offset and the number of particles flushed out during the same pressure pulse. If the per-pulse reactivation byproducts are not flushed out with $100 \%$ efficiency ( $n_{\text {produced }}>n_{\text {flushed }}$, where $n$ is the number of particles), this would lead to a transient clogging, yielding a pulse permeability contribution projecting below the trendline in Fig. 6(a). Conversely, if the accelerated flux flushes out both the newly produced wear products and the flocs that were not efficiently expelled during the previous pulses ( $n_{\text {produced }}<n_{\text {flushed }}$ ), this would be observed as the unusually large permeability increments (e.g. $\sim 5.4 \times 10^{-16} \mathrm{~m}^{2}$ ). Finally, if the particles produced are flushed out immediately with the same flux inducing the slip $\left(n_{\text {produced }}=\right.$ $\sim n_{\text {flushed }}$ ), this case would result in the mean per-pulse permeability increment predicted by the trendline $\left(\sim 1.5 \times 10^{-16} \mathrm{~m}^{2}\right.$; Fig. $\left.6 \mathrm{a}\right)$. Spontaneous alternation of these three cases may explain the apparent intermittency of the cumulative permeability increase in GRS1, assuming that this is introduced by particle mobilization. The intermittency would be cancelled out if all particles produced per-pulse were flushed out consistently, pulse after pulse. Permeability increase in experiments with Poorman schist samples does not show as obvious evidence for particle mobilization. Different hardness, fracture surface roughness, and mineralogy of the Green River shale sample from the Poorman schist samples may be responsible for the degree of resolution of the response. Nevertheless, assuming the similar processes responsible for the hydromechanical behavior of fractures between these experiments, the continuity of permeability increase in the PS experiments may indicate that the per-pulse balance between the wear produced and flushed out may have been more effectively maintained ( $n_{\text {produced }}=\sim n_{\text {flushed }}$ ).

The shape of the shear-associated cumulative permeability increase is linear in GRS1, whereas it follows a polynomial trend in the experiments with Poorman schist (Figs 6a and c). Such differences in shear permeability behavior is not uncommon as also shown with the permeability response during direct shearing applied in PS2 and PS3 (Figs 4b and c). More dramatically, Im et al. (2019) report cases where permeability initially increases sharply and then keeps increasing gradually during shear slip. Similarly, shear permeability increases initially with a steeper slope which turns into a more gradual increase in the PS experiments (Fig. 6c and Fig. S5).

Overall, we propose an interplay of multiple mechanisms as responsible for the observed dynamic permeability evolution. Our analysis suggests that a systematic rate-and-state friction type mechanism for sealing-breaching may be plausible for the rapidity and reproducibility of the observed dynamic cycles of permeability evolution. Flux-induced particle mobilization (clogging/unclogging) may be another mechanism aiding this process. When hydraulic injection induces shear reactivation, this is then overprinted by the effect of shear-driven dilation and the related permeability increase. The suspected effect of particle mobilization becomes especially aggravated with the slip-inducing injection pulses. The dramatic change in the rate of permeability increase with pressure may reflect the probable combined contribution of (i) shear dilation added to other (normal stress only) mechanisms involved and (ii) the magnified effect of particle mobilization. The actual contribution of each of these influences may be qualified by independently measuring the evolution of fracture aperture together with the mass accumulation rate and particle size distribution of fines flushed to the downstream outlet.

\subsection{Implications for natural fault systems and reservoir stimulation}

Laboratory faults are clear idealizations of the complexity and form of natural faults. Nevertheless, such highly constrained observations in the laboratory have illuminated key controlling processes implicated in field-scale observations of complex second-order friction (Chen \& Spiers 2016), stability (Leeman et al. 2016), healing (Yasuhara et al. 2005; Tenthorey \& Cox 2006) and permeability evolution (Im et al. 2018, 2019). In particular, our laboratory experiments are consistent to broad observations from natural hydraulic systems. The continuous sealing apparent in our experiments is directly analogous to permeability loss observed in the interseismic period over broad areas of California (Elkhoury et al. 2006) and in earthquake fault zones in China (Xue et al. 2013) — with this punctuated by sharp coseismic jumps in permeability (Elkhoury et al. 2006, Im et al. 2019). Furthermore, fault permeability enhancement driven by hydro-shearing has similarly been observed during hydraulic fracturing in the Barnett shale (Zoback et al. 2012) and in highly constrained fault-reactivation experiments (Guglielmi et al. 2015). Our work seeks to resolve the underlying mechanisms controlling these natural observations - a capability that is impossible 
at true field scale. Since the permeability enhancement observed in our experiments is shown to be related to shear-induced rupture and then dilation, knowledge of the roughness of faults at field scale is a key need in upscaling (Barton et al. 1985; Elsworth \& Goodman 1986; Elsworth \& Xiang 1989). Thus, the self-affine nature of roughness, spanning many decades of length scales (Power et al. 1987; Ishibashi et al. 2015; Brodsky et al. 2016; Candela \& Brodsky 2016) provides key information in upscaling the permeability response.

Fracture permeability evolves through the seismic cycle and is both a strong and sensitive signal of modes of deformation. Fracture closure or clogging during quiescence provides an opposite signal to those resulting from reductions in effective stress with those additionally exacerbated by shear reactivation providing a maximum increase in permeability following this permeability resetting. Our experiments confirm that both pore pressure dominant dynamic stressing and pressure-induced shear deformation can significantly perturb the permeability of natural faults (Elkhoury et al. 2006; Manga et al. 2012; Guglielmi et al. 2015). This supports the previous evidence that permeability increase may also be contributed by fault shear in addition to processes driven by normal deformation alone (Im et al. 2018). These experiments suggest that dynamic stress perturbations, whether injection-induced or triggered by distant earthquakes, may enhance fracture permeability by (i) stressdriven pore pressure increases and (ii) remotely triggered fault slip. The extended duration of natural fault repose primes the fault for permeability enhancement in both mechanisms.

Both this study and those of Im et al. $(2018,2019)$ show that the magnitude of shear permeability enhancement is primarily dependent on the magnitude of pre-slip sealing. We apply $>8 \mathrm{hr}$ of pre-slip sealing in this work but this is much smaller than the natural fault sealing duration that occurs in nature at higher stress and temperature. Hence, it is expected that the permeability enhancement of natural faults may be much higher than those in our experiments. For crustal depths up to a few kilometers, the pre-existing and stimulated permeability values in these experiments $\left(\sim 10^{-17}\right.$ $10^{-15} \mathrm{~m}^{2}$ ) correspond well with the mean crustal permeabilitydepth curve constructed based on geothermal-metamorphic data (Manning \& Ingebritsen 1999), and also with values from tight oil and gas reservoirs (Zhang et al. 2016). The fewfold transient shear-absent permeability enhancement in our experiments is consistent with the range of natural observations following intermediate to distant earthquakes, also with comparable strain amplitudes (e.g. Elkhoury et al. 2006). In contrast, shear failure may result in a $>100$-fold permeability increase in nature, leading to permeability values substantially larger than the mean crustal estimates (i.e. 'disturbed crust' in Ingebritsen \& Manning 2010; Gleeson \& Ingebritsen 2017). This is exemplified also following human intervention. The injection-stimulation of EGS reservoirs at Soultz and Basel resulted in permeability enhancement of more than two orders of magnitude relative to the pre-stimulated values (Evans et al. 2005; Häring et al. 2008), which may be comparable to the range of permeability increase in GRS1 in our study.

Despite the expected difference in magnitude, the qualitative permeability evolution is comparable to those achieved through injection-induced tensile opening and shear reactivation of natural fractures during reservoir stimulation (Cladouhos et al. 2009, 2013; Bao \& Eaton 2016). Previous examples of seismic events triggered by hydraulic injection (e.g. Mukuhira et al. 2008; Hofmann et al. 2019) show that efficient reservoir stimulation is possible only through a thorough understanding of the processes driving injection-induced shear slip linked to the subsequent seismicity. Our experiments provide direct evidence for the reduction in frictional strength of faults during injection stimulation as the mechanism of induced seismicity in the region penetrated by pore pressure diffusion. In addition to this, shear-reactivation-induced seismicity in the stimulated region may trigger seismic events in distal regions unpenetrated by the increased pore pressure, through dynamic perturbations of total stress. Recently, cyclic injection designs, together with the prominently applied multistage stimulation (Johri \& Zoback 2013), have been among the many candidate treatments attempting to minimize the seismicity associated with stimulation treatments. We note that the step-wise pore pressurizationdepressurization scheme applied in this study has similarities with advanced hydraulic stimulation treatments based on cyclic fluid injection schemes, such as fatigue hydraulic fracturing (Zang et al. 2013, 2019) and cyclic soft stimulation (Hofmann et al. 2018b, 2019). Diverse fracture permeability and frictional strength behavior described with these experiments might also be considered an addition to the laboratory scale observations (e.g. Hofmann et al. 2018a) in refining the cyclic stimulation protocols.

\section{CONCLUSIONS}

Our experimental results elucidate the complex interaction between the mechanisms controlling fracture permeability and friction evolution under the combined effect of dynamic stressing and shear deformation induced by fluid injection. Fracture permeability is enhanced with effective stress perturbations, scaling with the peak pore pressure both in the absence and presence of shear slip. The initiation of injection-induced shear slip accelerates permeability increase over the case where shear slip is absent. We demonstrate that dynamic permeability enhancement is reversible, as followed by a systematic fracture sealing, with these cycles of enhancement and recovery being eminently reproducible even in the very short term and absent shear reactivation. The proportionality of permeability increase to the peak pore pressure dictates that the amount of pre-pulse sealing controls the per-pulse permeability increment. Complex mechanisms are implied such as; chemo-mechanical compaction during repose, effects of pure fault-normal dilation, systematic rate-and-state friction type mechanisms of sealing-breaching, particle mobilization, and shear dilation. Permeability eventually recovers from the transient enhancement once the stress perturbations cease. These results have implications in better constraining the mechanics of dynamic earthquake triggering and in designing efficient stimulation treatments for hydrocarbon and enhanced geothermal reservoirs.

\section{ACKNOWLEDGEMENTS}

All experimental data are available as supplementary material. E.C. Yildirim acknowledges the financial support from Turkish Petroleum for her M.S. studies upon which this work is based.

\section{REFERENCES}

Asahina, D., Pan, P., Sato, M., Takeda, M. \& Takahashi, M., 2019. Hydraulic and mechanical responses of porous sandstone during pore pressureinduced reactivation of fracture planes: an experimental study, Rock Mech. Rock Eng., 52, 1645-1656.

Bao, X. \& Eaton, D.W., 2016. Fault activation by hydraulic fracturing in western Canada, Science, 354(6318), 1406-1409. 
Barton, N., Bandis, S. \& Bakhtar, K., 1985. Strength, deformation and conductivity coupling of rock joints, Int. J. Rock Mech. Min. Sci., 22(3), 121-140.

Baumberger, T. \& Caroli, C., 2006. Solid friction from stick-slip down to pinning and aging, $A d v$. Phys., 55(3-4), 279-348.

Brodsky, E.E., Kirkpatrick, J.D. \& Candela, T., 2016. Constraints from fault roughness on the scale-dependent strength of rocks, Geology, 44(1), 1922.

Brodsky, E.E., Roeloffs, E., Woodcock, D., Gall, I. \& Manga, M., 2003. A mechanism for sustained groundwater pressure changes induced by distant earthquakes, J. geophys. Res., 108(B8), 2390.

Byerlee, J.D., 1978. Friction of rocks, Pure appl. Geophys., 116(4-5), 615626.

Caddey, S.W., Bachman, R.L., Campbell, T.J., Reid, R.R. \& Otto, R.P., 1991. The Homestake Gold Mine: an early Proterozoic iron-formationhosted gold deposit, Lawrence County, South Dakota, in Geology and Resources of Gold in the United States, pp. J1-J67, eds Shawe, D.R., Ashley, R.P. \& Carter, L.M.H., US Geological Survey Bulletin 1857-J, https://doi.org/10.3133/b1857J

Candela, T. \& Brodsky, E.E., 2016. The minimum scale of grooving on faults, Geology, 44(8), 603-606.

Candela, T., Brodsky, E.E., Marone, C. \& Elsworth, D., 2014. Laboratory evidence for particle mobilization as a mechanism for permeability enhancement via dynamic stressing, Earth planet. Sci. Lett., 392, 279-291.

Candela, T., Brodsky, E.E., Marone, C. \& Elsworth, D., 2015. Flow rate dictates permeability enhancement during fluid pressure oscillations in laboratory experiments, J. geophys. Res., 120, 2037-2055.

Chen, J. \& Spiers, C.J., 2016. Rate and state frictional and healing behavior of carbonate fault gouge explained using microphysical model, J. geophys. Res., 121, 8642-8665.

Chen, Z., Narayan, S., Yang, Z. \& Rahman, S., 2000. An experimental investigation of hydraulic behaviour of fractures and joints in granitic rock, Int. J. Rock Mech. Min. Sci., 37(7), 1061-1071.

Chen, J., Verberne, B.A. \& Spiers, C.J., 2015. Interseismic re-strengthening and stabilization of carbonate faults by "non-Dieterich" healing under hydrothermal conditions, Earth planet. Sci. Lett., 423, 1-12.

Cladouhos, T., Petty, S., Larson, B., Iovenitti, J., Livesay, B. \& Baria, R., 2009. Toward more efficient heat mining: a planned enhanced geothermal system demonstration project, Geotherm. Resour. Council Trans., 33, $165-170$.

Cladouhos, T. et al., 2013. Microseismic monitoring of Newberry volcano EGS demonstration, in Proceedings of the 38th Workshop on Geothermal Reservoir Engineering, Stanford Geothermal Program Workshop Rep., Vol. 38, pp. 778-786, Stanford University, Stanford, CA.

Dove, P.M. \& Crerar, D.A., 1990. Kinetics of quartz dissolution in electrolyte solutions using a hydrothermal mixed flow reactor, Geochim. Cosmochim. Acta., 54(4), 955-969.

Elkhoury, J.E., Brodsky, E.E. \& Agnew, D.C., 2006. Seismic waves increase permeability, Nature, 441(7097), 1135-1138.

Elkhoury, J.E., Niemeijer, A., Brodsky, E.E. \& Marone, C., 2011. Laboratory observations of permeability enhancement by fluid pressure oscillation of in situ fractured rock, J. geophys. Res., 116, B02311, doi:10.1029/2010JB007759.

Elsworth, D. \& Goodman, R.E., 1986. Characterization of rock fissure hydraulic conductivity using idealized wall roughness profiles, Int. J. Rock Mech. Min. Sci. Geomech. Abstr., 23(3), 233-243.

Elsworth, D. \& Xiang, J., 1989. A reduced degree of freedom model for permeability enhancement in blocky rock, Geothermics, 18(5-6), 691709.

Evans, K.F., Genter, A. \& Sausss, J., 2005. Permeability creation and damage due to massive fluid injections into granite at $3.5 \mathrm{~km}$ at Soultz: 1. Borehole observations, J. geophys. Res., 110, B04203, doi:10.1029/2004JB003168.

Fang, Y., Elsworth, D., Wang, C., Ishibashi, T. \& Fitts, J.P., 2017. Frictional stability-permeability relationships for fractures in shales, J. geophys. Res., 122, 1760-1776.

Faoro, I., Elsworth, D. \& Marone, C., 2012. Permeability evolution during dynamic stressing of dual permeability media, J. geophys. Res., 117, B01310, doi:10.1029/2011JB008635.
Faoro, I., Niemeijer, A., Marone, C. \& Elsworth, D., 2009. Influence of shear and deviatoric stress on the evolution of permeability in fractured rock, $J$. geophys. Res., 114(1), doi:10.1029/2007JB005372.

Gleeson, T. \& Ingebritsen, S.E., 2017. Introduction, in Crustal Permeability, pp. 1-5, eds Gleeson, T. \& Ingebritsen, S.E., doi:10.1002/9781119166573.ch1.

Goebel, T.H.W. \& Brodsky, E.E., 2018. The spatial footprint of injection wells in a global compilation of induced earthquake sequences, Science, 361(6405), 899-904.

Guglielmi, Y., Cappa, F., Avouac, J., Henry, P. \& Elsworth, D., 2015. Seismicity triggered by fluid injection-induced aseismic slip, Science, 348(6240), $1224-1226$.

Gutierrez, M., Øino, L. \& Nygaard, R., 2000. Stress-dependent permeability of a de-mineralised fracture in shale, Mar. Pet. Geol., 17(8), 895-907.

Häring, M.O., Schanz, U., Ladner, F. \& Dyer, B.C., 2008. Characterisation of the Basel 1 enhanced geothermal system, Geothermics, 37, 469-495.

Hofmann, H. et al., 2018a. Comparison of cyclic and constant fluid injection in granitic rock at different scales, in Paper presented at $52^{\text {nd }}$ US Rock Mechanics / Geomechanics Symposium, Seattle, WA, USA, ARMA 18691.

Hofmann, H., Zimmermann, G., Zang, A. \& Min, K.-B., 2018b. Cyclic soft stimulation (CSS): a new fluid injection protocol and traffic light system to mitigate seismic risks of hydraulic stimulation treatments, Geotherm. Ener, 6(1), 27.

Hofmann, H. et al., 2019. First field application of cyclic soft stimulation at the Pohang Enhanced Geothermal System site in Korea, Geophys. J. Int., 217(2), 926-949.

Im, K., Elsworth, D. \& Fang, Y., 2018. The influence of preslip sealing on the permeability evolution of fractures and faults, Geophys. Res. Lett., 45, $166-175$.

Im, K., Elsworth, D. \& Wang, C., 2019. Cyclic permeability evolution during repose then reactivation of fractures and faults, J. geophys. Res., 124, 4492-4506.

Ingebritsen, S.E. \& Manning, C.E., 2010. Permeability of the continental crust: Dynamic variations inferred from seismicity and metamorphism, Geofluids, 10, 193-205.

Ishibashi, T., Watanabe, N., Hirano, N., Okamoto, A. \& Tsuchiya, N., 2015. Beyond-laboratory-scale prediction for channeling flows through subsurface rock fractures with heterogeneous aperture distributions revealed by laboratory evaluation, J. geophys. Res., 120, 106-124.

Johri, M. \& Zoback, M.D., 2013. The evolution of stimulated reservoir volume during hydraulic stimulation of shale gas formations, in Paper presented at Unconventional Resources Technology Conference, Denver, CO, USA.

Leeman, J.R., Saffer, D.M., Scuderi, M.M. \& Marone, C., 2016. Laboratory observations of slow earthquakes and the spectrum of tectonic fault slip modes, Nat. Commun. 7, 11104.

Liu, W. \& Manga, M., 2009. Changes in permeability caused by dynamic stresses in fractured sandstone, Geophys. Res. Lett., 36, L20307, doi:10.1029/2009GL039852.

Manga, M., Beresnev, I., Brodsky, E.E., Elkhoury, J.E., Elsworth, D., Ingebritsen, S.E., Mays, D.C. \& Wang, C.-Y., 2012. Changes in permeability caused by transient stresses: field observations, experiments and mechanisms, Rev. Geophys., 50, RG2004, doi:10.1029/2011RG000382.

Manning, C.E. \& Ingebritsen, S.E., 1999. Permeability of the continental crust: Implications of geothermal data and metamorphic systems, Rev. Geophys., 37, 127-150,

Marone, C., 1998. Laboratory-derived friction laws and their application to seismic faulting, Аnпи. Rev. Earth Planet. Sci., 26(1), 643-696.

McGarr, A., Simpson, D. \& Seeber, L., 2002. Case histories of induced and triggered seismicity, in International Handbook of Earthquake and Engineering Seismology, Part A, Vol. 81, pp. 647-661, eds Lee, W.H.K., Kanamori, H., Jennings, P.C. \& Kisslinger, C., Academic Press.

Mitchell, T.M. \& Faulkner, D.R., 2008. Experimental measurements of permeability evolution during triaxial compression and initially intact crystalline rocks and implications for fluid flow in fault zones, J. geophys. Res. 113, B11412, doi:10.1029/2008JB005588. 
Mukuhira, Y., Asanuma, H., Niitsuma, H., Schanz, U. \& Haring, M., 2008. Characterization of microseismic events with larger magnitude collected at Basel, Switzerland in 2006, Geotherm. Resour. Council Trans., 32, 87-94.

Mukuhira, Y., Moriya, H., Ito, T., Asanuma, H. \& Haring, M., 2017. Pore pressure migration during hydraulic stimulation due to permeability enhancement by low-pressure subcritical fracture slip, Geophys. Res. Lett., 44, 3109-3118.

Nemoto, K., Moriya, H., Niitsuma, H. \& Tsuchiya, N., 2008. Mechanical and hydraulic coupling of injection-induced slip along pre-existing fractures, Geothermics, 37(2), 157-172.

Niemeijer, A., Marone, C. \& Elsworth, D., 2008. Healing of simulated fault gouges aided by pressure solution: results from rock analogue experiments, J. geophys. Res., 113, B04204, doi:10.1029/2007JB005376.

Niemeijer, A., Marone, C. \& Elsworth, D., 2010. Frictional strength and strain weakening in simulated fault gouge: competition between geometrical weakening and chemical strengthening, J. geophys. Res., 115, B10207, doi:10.1029/2009JB000838.

Power, W.L., Tullis, T.E., Brown, S.R., Boitnott, G.N. \& Scholz, C.H., 1987. Roughness of natural fault surfaces, Geophys. Res. Lett., 14, 29-32.

Roberts, P.M., 2005. Laboratory observations of altered porous fluid flow behavior in Berea sandstone induced by low-frequency dynamic stress stimulation, Acoust. Phys., 51, 140-148.

Roeloffs, E., 1998. Persistent water level changes in a well near Parkfield, California, due to local and distant earthquakes, J. geophys. Res., 103(B1), 869-889.

Rojstaczer, S. \& Wolf, S., 1992. Permeability changes associated with large earthquakes: an example from Loma Prieta, California, Geology, 20(3), 211-214.

Sandvik, E.I. \& Mercer, J.N., 1990. Primary migration by bulk hydrocarbon flow, Org. Geochem., 16(1-3), 83-89.

Segall, P. \& Rice, J., 1995. Dilatancy, compaction and slip instability of a fluid-infiltrated fault, J. geophys. Res., 100(B11), 22 155-22 171.

Self, J.G., Johnson, R.C., Brownfield, M.E. \& Mercier, T.J., 2010. Stratigraphic cross sections of the Eocene Green River Formation in the Piceance Basin, northwestern Colorado, in Oil Shale and Nahcolite Resources of the Piceance Basin, Colorado, ed. U.S. Geological Survey Oil Shale Assessment Team, U.S. Geological Survey Digital Data Series 69Y, chapter. 5. Retrieved from https://pubs.usgs.gov/dds/dds-069/dds-06 9-y/REPORTS/69_Y_CH_5.pdf

Shokouhi, P., Jin, J., Wood, C., Rivière, J., Madara, B., Elsworth, D. \& Marone, C., 2019. Dynamic stressing of naturally fractured rocks: on the relation between transient changes in permeability and elastic wave velocity, Geophys. Res. Lett., 47, doi:10.1029/2019GL083557.

Steinbrugge, K.V. \& Moran, D.F., 1954. c, Bull. seism. Soc. Am., 44(2B), 201-462.

Tenthorey, E. \& Cox, S.F., 2006. Cohesive strengthening of fault zones during the interseismic period: an experimental study, J. geophys. Res., 111(B09202), 1-14.

Teufel, L.W., 1987. Permeability changes during shear deformation of fractured rock, in Paper Presented at 28th US Symposium on Rock Mechanics, Tucson, USA, pp. 473-480.

van der Elst, N.J. \& Brodsky, E.E., 2010. Connecting near-field and far-field earthquake triggering to dynamic strain, J. geophys. Res., 115, B07311, doi:10.1029/2009JB006681.

Voytov, G.I., Osika, D.G., Grechukhina, T.G. \& Plotnikov, I.A., 1972. Some geological and geochemical consequences of the Daghestan earthquake of May 14, 1970, Trans. USSR Acad. Sci., Earth Sci. Sect., 202, 576-579.

Wang, C., Elsworth, D. \& Fang, Y., 2017. Influence of weakening minerals on ensemble strength and slip stability of faults, J. geophys. Res., 122, 7090-7110.

Witherspoon, P.A., Wang, J.S.Y., Iwai, K. \& Gale, J.E., 1980. Validity of cubic law for fluid flow in a deformable rock fracture, Water Resour. Res., 16(6), 1016-1024.

Xue, L. et al., 2013. Continuous permeability measurements record healing inside the Wenchuan earthquake fault zone, Science, 340(6140), 15551559.
Yasuhara, H., Elsworth, D. \& Polak, A., 2004. Evolution of permeability in a natural fracture: significant role of pressure solution, J. geophys. Res., 109, B03204, doi:10.1029/2003JB002663.

Yasuhara, H. \& Elsworth, D., 2008. Compaction of a fracture moderated by competing roles of stress corrosion and pressure solution, Pure appl. Geophys., 165(7), 1289-1306.

Yasuhara, H., Marone, C. \& Elsworth, D., 2005. Fault zone restrengthening and frictional healing: the role of pressure solution, J. geophys. Res., 110, B06310, doi:10.1029/2004JB003327.

Ye, Z. \& Ghassemi, A., 2018. Injection-induced shear slip and permeability enhancement in granite fractures, J. geophys. Res., 123, 9009-9032.

Ye, Z., Ghassemi, A. \& Kneafsey, T., 2020. Deformation, failure and permeability evolution of sealed fractures in EGS Collab Poorman schist, in Paper presented at $45^{\text {th }}$ Workshop on Geothermal Reservoir Engineering, Stanford, CA, USA.

Yeo, I.W., De Freitas, M.H. \& Zimmerman, R.W., 1998. Effect of shear displacement on the aperture and permeability of a rock fracture, Int. J. Rock Mech. Min. Sci., 35(8), 1051-1070.

Yildirim, E.C., Im, K. \& Elsworth, D., 2018. Co-evolution of fracture permeability and friction in rocks from the EGS Collab Experiment 1 site, in Paper presented at 52nd US Rock Mechanics / Geomechanics Symposium, Seattle, WA, USA, ARMA 18-1360.

Yildirim, L.T.O., Elsworth, D. \& Wang, J.Y., 2019. Permeability and rigidity of Green River shale before and after interaction with water, in Paper presented at $53^{\text {rd }}$ US Rock Mechanics / Geomechanics Symposium, New York City, NY, USA, ARMA 19-112.

Zang, A., Yoon, J.S., Stephansson, O. \& Heidbach, O., 2013. Fatigue hydraulic fracturing by cyclic reservoir treatment enhances permeability and reduces induced seismicity, Geophys. J. Int., 195(2), 1282-1287.

Zang, A., Zimmermann, G., Hofmann, H., Stephansson, O., Min, K.B. \& Kim, K.Y., 2019. How to reduce fluid-injection induced seismicity, Rock Mech. Rock Eng., 52(2), 475-493.

Zhang, X-S., Wang, H-J., Ma, F., Sun, X-C., Zhang, Y. \& Song, Z-H., 2016. Classification and characteristics of tight oil plays, Petrol. Sci., 13, 18-33.

Zoback, M.D., Kohli, A., Das, I. \& McClure, M., 2012. The importance of slow slip on faults during hydraulic fracturing stimulation of shale gas reservoirs, in Paper presented at SPE Americas Unconventional Resources Conference, Pittsburgh, PA, USA, doi:10.2118/155476-MS.

\section{SUPPORTING INFORMATION}

Supplementary data are available at $G J I$ online.

Table S1. List of experiments and the procedures followed after the initial shear-in and the extended hold periods.

Figure S1. Fracture permeability and friction evolution at dynamic stressing, hold and slide in PS1. Panels (a), (b), and (c) exhibit friction/displacement, permeability, and pore pressure changes. This part of the experiment belongs to the pore pressure stepping portion of PS1 after the initial long hold. Panel (b) is identical to Figure 4d. Figure S2. Fracture permeability and friction evolution at dynamic stressing, hold and slide in PS2. Panels (a), (b), and (c) exhibit friction/displacement, permeability, and pore pressure changes. This part of the experiment belongs to the pore pressure stepping portion of PS2 after the initial long hold. Panel (b) is identical to Figure 4c. Figure S3. Fracture permeability and friction evolution at dynamic stressing, hold and slide in PS3. Panels (a), (b), and (c) exhibit friction/displacement, permeability, and pore pressure changes. This part of the experiment belongs to the pore pressure stepping portion of PS3 after the initial long hold. Panel (b) is identical to Figure 4b. Figure S4. Fracture permeability and friction evolution at dynamic stressing and post-stimulation hold in GRS1. Panels (a), (b), and (c) exhibit friction/displacement, permeability, and pore pressure changes. This part of the experiment belongs to the pore pressure stepping portion of GRS1 after the initial long hold. Panel (b) is identical to Figure 4a. 
Figure S5. Continuation of Figure 6. Cumulative permeability increase $\left(k_{n}-k_{0}\right.$; left $)$ and per-pulse permeability increments $\left(k_{n}-\right.$ $\mathrm{k}_{\mathrm{n}-1}$; right) versus differential pore pressure for all experiments, showing pressure-pulse-driven permeability evolution both in the absence and then presence of flow-induced shear slip. Insets in panels (f) and (h) include permeability increment due to $\mathrm{Pp}_{1}$ in both experiments. Note the missing measurement at $P p=950 \mathrm{kPa}$ in PS2

Figure S6. Fracture permeability and friction evolution at dynamic stressing in experiment PS0 with Poorman schist. Panels (a), (b), and (c) exhibit friction/displacement, permeability, and pore pressure changes. This is one of the earlier pore pressure stepping experiments that we conducted before the more extended experiments that we report in the manuscript. Experimental procedure of this prototype is similar to the procedure reported in this study, only with fewer pressure steps in PS0. Following a $\sim 10$ hours long "seating-in" over the applied hold, this experiment initiates with shear loading (sharp increase in the top panel; shaded with orange) in order to reset shear stress from the diminished magnitude during the hold (similar to PS1). The concurrent increase in displacement at the initial loading is not an actual slip, but an artificial response arising due to the compaction of experimental materials at shear loading. Pore pressure pulses are applied with a duration of $5 \mathrm{~s}$ and successively incremented every $120 \mathrm{~s}$ by $50 \mathrm{kPa}\left(\mathrm{Pp}_{1}=262 \mathrm{kPa}\right.$ and $\mathrm{Pp}_{6}=512 \mathrm{kPa}$ ). Fracture surfaces of PS0 are ground with \#600 grit abrasive powder during sample preparation (smoother than the other three schist samples). Final fracture permeability $\left(7.5 \times 10^{-14}\right.$ $\mathrm{m}^{2}$ ) as a result of 6 pulses is $\sim 5.5$ times the initial permeability $\left(1.4 \times 10^{-14} \mathrm{~m}^{2}\right)$.

Please note: Oxford University Press is not responsible for the content or functionality of any supporting materials supplied by the authors. Any queries (other than missing material) should be directed to the corresponding author for the paper. 